تمرينات الكارديو وتأثثرها على حجم الدهون ومؤشر كتلة الجسم وبعض المتغيرات الفسيولوجية لاي الممارسات بمراكز اللياقة البدنية بالدمام

أ.م.د/ إيمان وجيه محمد

كليه التربيه الرياضية بنات

جامعل حلوان - مصر الرئر بنات

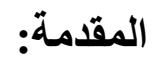

أصبح التدريب علماً له اصوله وقواعده وطرقه المختلفة التي تساعد الفرد للوصول إلى أعلى

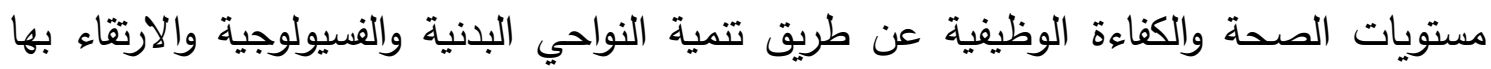

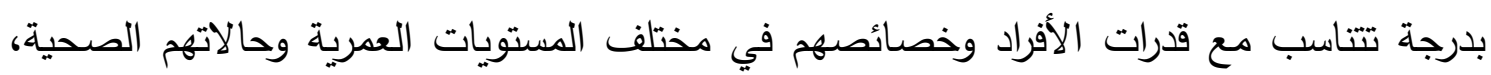
حيث يذكر كلاً من "جوناسان مايرز" Jonathan Myers (2003)، "وكالابرو بي" (2008) Masi S, et al و (2009) Calabro, P. الماضية ، قد أشارت تقارير بعض المنظمات العالمية مثل مركز السيطرة على الأمراض والوقاية

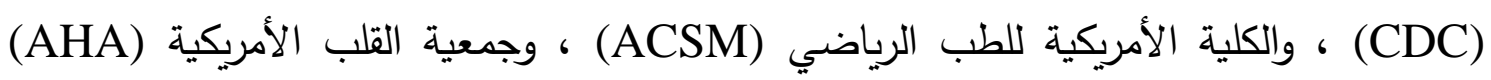

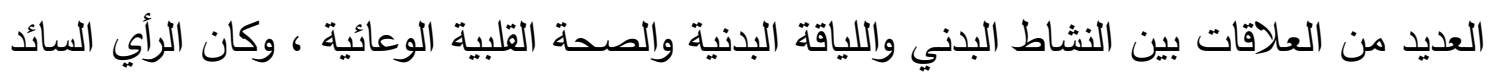

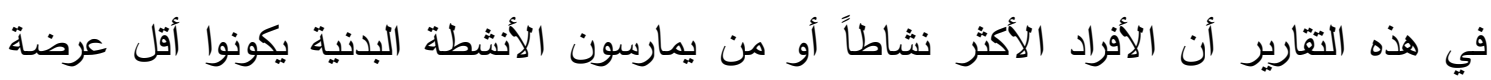

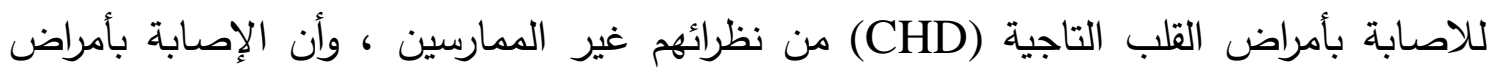

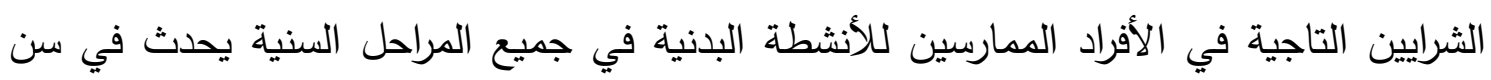

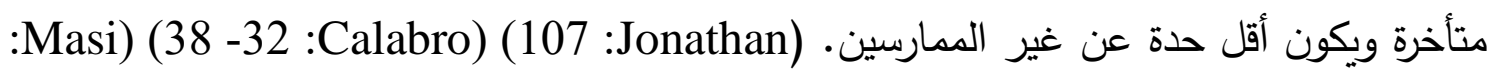

يمكن للنشاط البدني أن يقلل من خطر الإصابة بأمراض القلب والأوعية الاموية ، وينصح

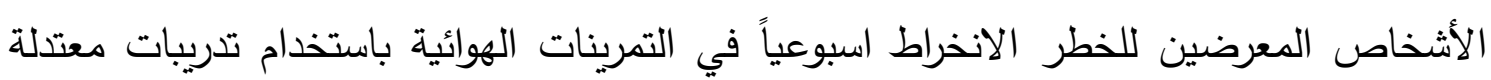

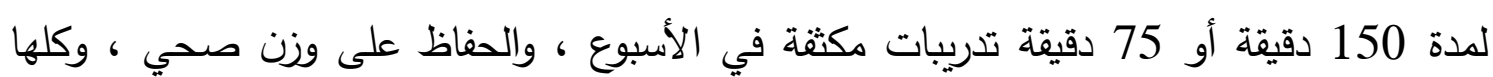
تعتبر تدابير وقائية تعمل على تقليل مخاطر الإصابة بأمراض القلب والأوعية الدموية . (206:Clinical guideline)

وتعد تمرينات الكارديو من الأنثطة الهوائية التي تستخدم العضلات فيها الأكسجين والجلوكوز

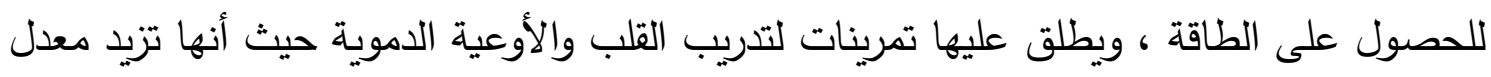

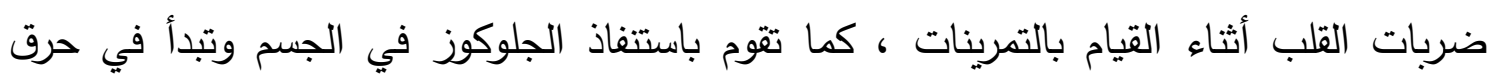

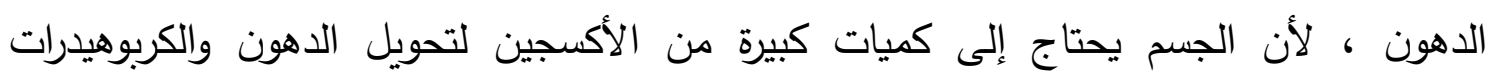

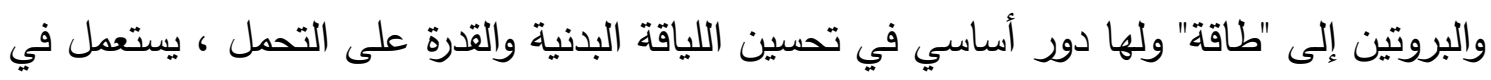


ذلك عدة تدرببات تقوم اساسًا بزيادة النشاط القلبي التنفسي الذي يزيد من قدرة الجسم على حرق السعرات الحرارية ، كما تؤدي لزيادة الجهد القلبي ، وكثرة أنواع تمارين الكارديو، تجعل الفرد لا يشعر بالملل من الرياضة ، لأن الفرد يستطيع أداؤها بأي مكان يريد ولديه القدرة على التوزيع لرديع والاختيار منها (تمرينات المشي والهرولة والجري بسرعات مختلفة وركوب الدراجات واستخدام صندوق الخطو)، فهي تؤدي حرة أو باستخدام أدوات ، وقد تؤدي تمرينات الكارديو في جميع الأوساط ، في الوسط الخارجي أو في الماء . وتعتبر الموسيقي من أدوات الكارديو والتي تعمل على تحفيز المتدربين وتتظيم الايقاع الحركي المستخدم في التمرين فيساعد على ضبط سرعة الأداء (23شبكة المعلومات) (24 شبكة المعلومات) (26شبكة المعلومات) (30 شبكة المعلومات) وتتلخص انواع تمارين الكارديو في نوعين : الأول هو تمارين الكارديو عالية الكثافة HIIT والتي تعمل على زيادة أكسجين العضلات وهذا يعني استشفاء أسرع بعد التمرين كما تعمل على نشاط الدورة الدموية، والنوع الآخر هو تمارين الكارديو منخفضة الكثافة LiSS والتي تعمل على حرق الدهون بسرعة وأكسدة الدهون وتحويلها إلى طاقة كما تعمل على افراز هرمون السعادة (31شبكة

(المعلومات)

مشكلة الاراسة:

انتشرت في الآونة الأخيرة تمرينات الكارديو والتي اعتبرت من اهم التمارين الرياضية التي تمارس

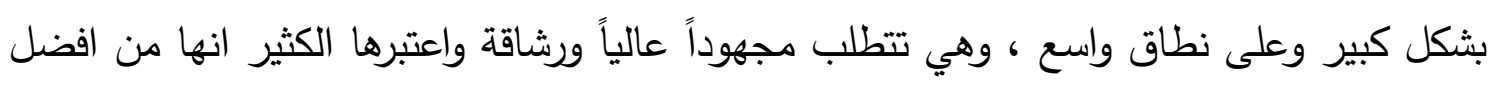
التمارين لجسم الإنسان لأنها تعتمد بشكل رئيسي على حرق الأكسجين وسكر الدم في الجسم لانتاج الطاقة وبالتالي هي من أهم التمارين التي تمارس لخسارة الوزن وحرق الدهون في مختلف انحاء الجسم.

ومن خلال متابعة تطورات التريب البدني الحديث عامة ، والاطلاع على بعض الدراسات السابقة الحديثة المشابهة التي تعتني بموضوع التدرببات الحديثة خاصة ، لوحظ تفاوت أغراض استخدام التدربات الحديثة من قبل المدربين ، كإسلوب ووسيلة لتنمية وتطوير القدرات البدنية والفسيولوجية المتتوعة. حيث استخدمها البعض لتطوير بعض القدرات الأكسجينية ، والبعض الآخر استخدمها كإسلوب لتطوير القدرات اللاكسجينية ؛ وذلك إيمانًا منهم أن التدريبات الحديثة لها القدرة في إحداث تغيرات وتكيفات بدنية وفسيولوجية إيجابية تخدم الجانب الذي يحاول تطويره. وهذا يظهر تفاوتاً واضحاً في وجهات النظر بأهمية تمرينات الكارديو كأسلوب في تطوير القدرات البدنية والفسيولوجية بنوعيها الأكسجينية واللأكسجينية. 
ومن هنا جاءت مشكلة الدراسة للتعرف على أثر تمرينات الكارديو على حجم الدهون ومؤشر كتلة الجسم وبعض المتغيرات الفسيولوجية لدي الممارسات بمراكز اللياقة البدنية والتي استهدفت جودة الصحة وتقليل نسبة الدهون بالجسم. أهمية الدراسة :

تستمد هذه الدراسة أهميتها من كونها تعد من الدراسات الحديثة القليلة التي تتاولت تأثير تمرينات الكارديو على الممارسات في مراكز اللياقة البدنية في شتى ألوان النشاط الرياضي بدنياً وفسيولوجياً ، وقد اخصت الممارسات في مراكز اللياقة البدنية في محافظة الدمام وفى ضوء علم الباحثة تستمد الدراسة اهميتها من خلال النقاط التالية: 1- تثيد الدراسة في توفير معلومات معرفية متتوعة حول تمرينات الكارديو وتأثيره بدنياً وفسيولوجيا على المتدرب الرياضي.

2- تساعد هذه الدراسة في تسليط الضوء على اهمية تمرينات الكارديو واثرها على بعض المتغيرات الفسيولوجية.

3- توجه هذه الدراسة المدربين إلى طريقة جديدة من الطرق المستخدمة في تقليل نسبة الاهون بالجسم. 4- تقتح هذه الدراسة المجال للباحثين بإجراء المزيد من الأبحاث التي تتتاول موضوع التدريبات الحديثة بشكل عام وتمرينات الكارديو بشكل خاص. أهداف الدراسةة: - 2 هدفت الدراسة إلى التعرف على تأثير تمرينات الكارديو على:

1- الفروق بين القياسين القبلي والبعدي في متغيرات الدراسة الفسيولوجية (حجم الدهون ، ومؤشر كتلة الجسم ، والقدرة اللأكجسينية ، والسعة اللأكسجينية ، والحد الأقصي لإستهلاك الأكسجين النسبي ، معدل الأيض الأساسي) لدى أفراد المجموعة التجريبية. 2- الفروق بين القياسين القبلي والبعدي في متغيرات الدراسة الفسيولوجية (حجم الدهون ، ومؤشر كتلة الجسم ، والقدرة اللأكسجينية ، والسعة اللأكسجينية ، والحد الأقصي لإستهلاك الأكسجين النسبي ، ومعدل الأيض الأساسي) لدي أفراد المجموعة الضابطة. 3- الفروق في القياس البعدي بين افراد المجموعتين التجرببية والضابطة على متغيرات الدراسة الفسيولوجية (حجم الدهون ، ومؤشر كتلة الجسم ، والقدرة اللأكسجينية ، والسعة اللاأكسجينية ، والحد الأقصي لإستهلاك الأكسجين النسبي ، ومعدل الأيض الأساسي) 
سعت الدراسة للإجابة عن التساؤلات الآتية:

1- هل توجد فروق ذات دلالمة إحصائية بين القياسين القبلي والبعدي في متغيرات الدراسـة

الفسـيولوجية (حجـم الـــون ، ومؤشـر كتلـة الجسـم ، والقـدرة اللأكسـبنينية ، والسـعة اللأكسجينية ، والحد الأقصسي لإستهلاك الأكسجين النسبي ، ومعدل الأيض الأساسي) لاي أفراد المجموعة التجرببية؟

2- هل توجد فروق ذات دلالمة إحصائية بين القياسين القبلي والبعدي في متغيرات الدراسـة الفسـيولوجية (حجـم الـدهون ومؤشـر كتلـة الجسـم ، والقـدرة اللاأكسـجينية ، والسـعة اللأكسجينية، والحد الأقصسي لإستهلاك الأكسجين النسبي ، ومعدل الأيض الأساسي) لدي أفراد المجموعة الضابطة؟ 3- هـل توجد فروق ذات دلالــة إحصـائية بـين أفراد المجمـوعتين التجريبيـة والضـابطة في القياس البعدي على جميع متغيرات الدراسـة الفسيولوجية (حجم الدهون ، ومؤشر كتلة الجسم ، والقدرة اللأكسجينية ، والسعة اللاأكسينية والحد الأقصسي لإستهلاك الأكسجين

$$
\begin{aligned}
& \text { النسبي ، ومعدل الأيض الأساسي )؟ } \\
& \text { متغيرات الدراسة : } \\
& \text { المتغير المستقل: } \\
& \text { برنامج مقترح لتمرينات الكارديو } \\
& \text { المتغيرات التابعة: } \\
& \text { كتلة الشحوم. } \\
& \text { - - - مؤشر كتلة الجسم. } \\
& \text { - - - معدل الأيض الأساسي. } \\
& \text { - - - مالقدرة اللأكسجينية. } \\
& \text { - - - - مأسعة اللأكسجينية. } \\
& \text { - - الحد الأقصي لإستهلاك الأكسجين النسبي. } \\
& \text { مصطاح الدراسة : }
\end{aligned}
$$

(Wilmore et al., القدرة اللاأكسجينية Anaerobic Power: عرفها "ويلمور وآخرون (2008 بأنها اقصي طاقة يكمن إنتاجها عند ممارسة الأنشطة الرياضية التي يستمر الأداء فيها حتي (30) ثانية أو أقل (Wilmore: 204: (204). 
السعة اللاأكسجينية Anaerobic Capacity: عرفها "بهاء الدين سلامة" (2008) وهي القدرة على الإحتفاظ أو تكرار إنقباضات عضلية قصوى إعتمادًا على إنتاج الطاقة اللاأكسجيني

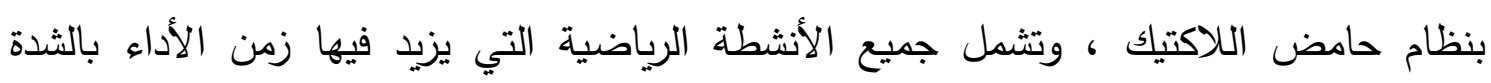

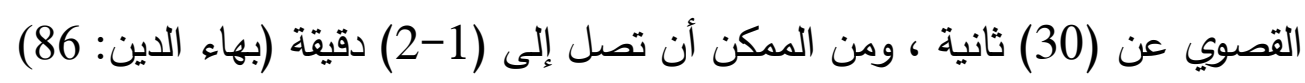

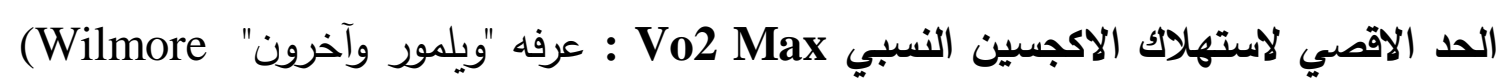

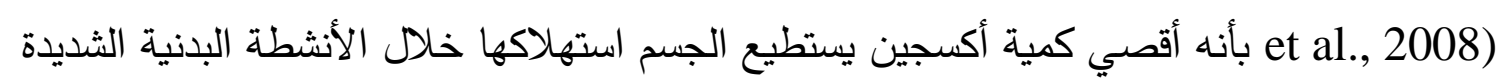

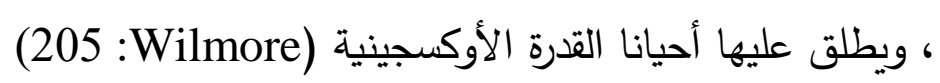
معدل الأيض الأساسي (BMR-Basal Metabolic Rat) : : عرفها "ويلمور وآخرون" (Wilmore et al., 2008)

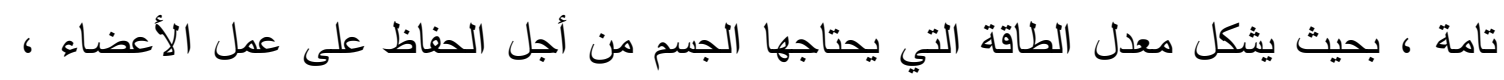
وإبقاءك على قيد الحياة بدون أي مجهود إضافي (Wilmore:

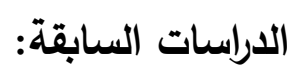
1- قامـت أمل حسين السيد (2003) بدراسة استهدفت التعرف على تأثير ممارسة التدريب الهوائي على زيادة البروتينات الدهنية مرتفعة ومنخفضة الكثافة في الدم للوقاية من أمراض

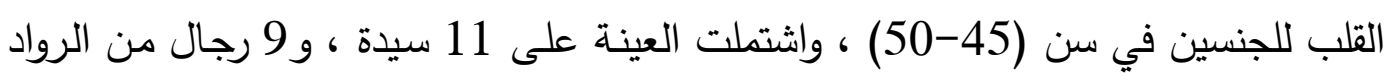

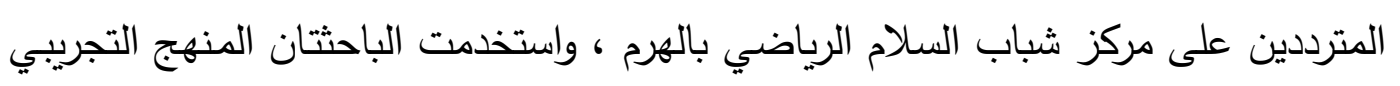

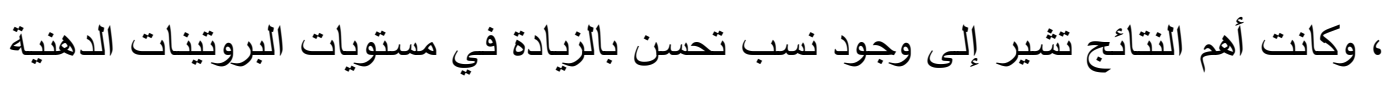

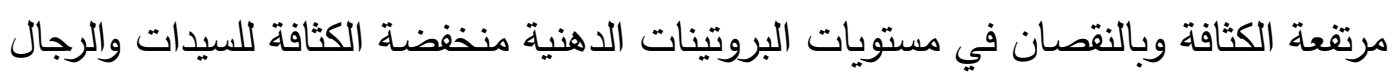

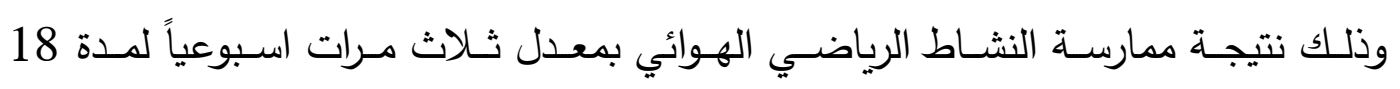
أسبوع(أمل حسين). 2- قامت سها عبد الله السملاوى (2007) بدراسة بهدف التعرف على تأثير برنامج تمرينات

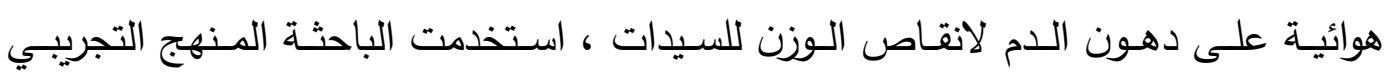

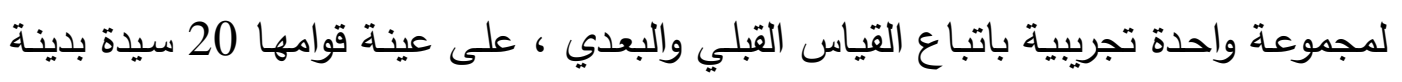
وتتراوح اعمارهن من 30-40 سنة ، واشارت اهم النتائج إلى أن ممارسة التمرينات الهوائية

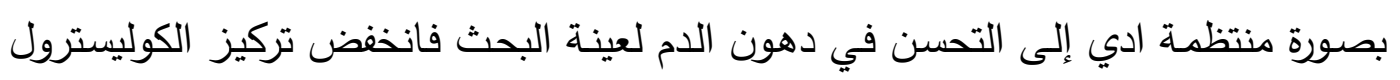

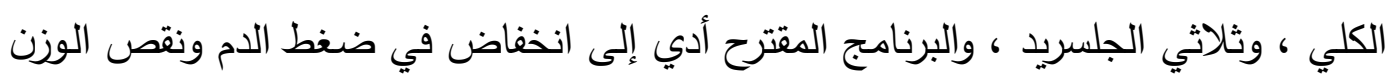

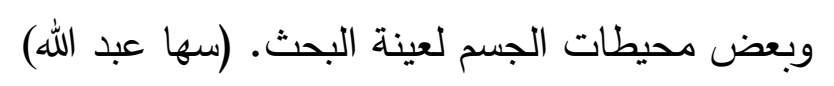


3- قامست سوسـن فرغلـي أحمـد (2011) بدراسـة بهدف التعرف على تأثير برنامج تدريبي

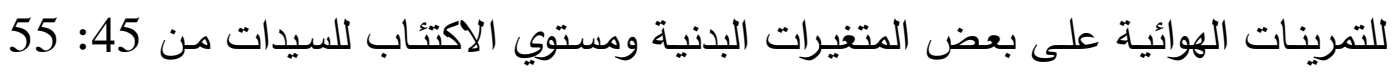

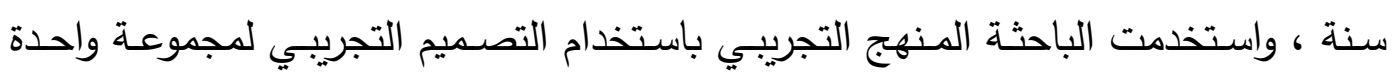

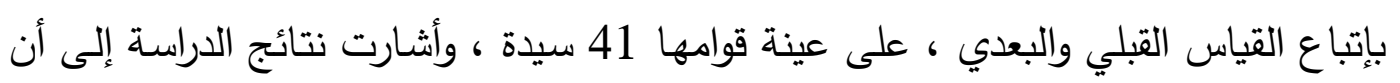

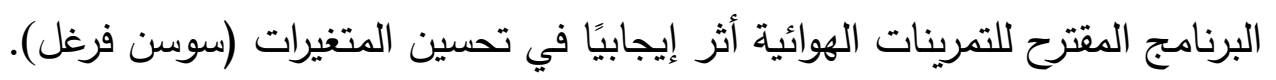
4- قامت عايدة محمد حسين (2012) بدراسة بهدف التعرف على تأثير برنامج التمرينات

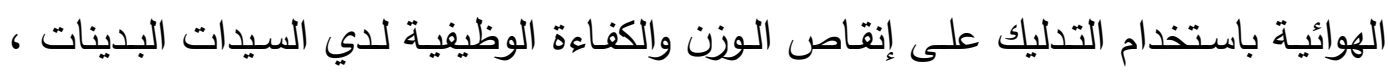

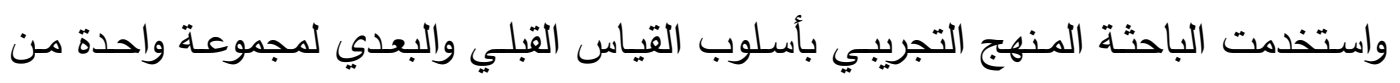

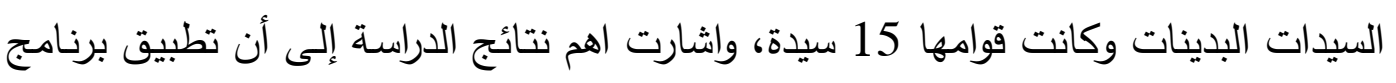

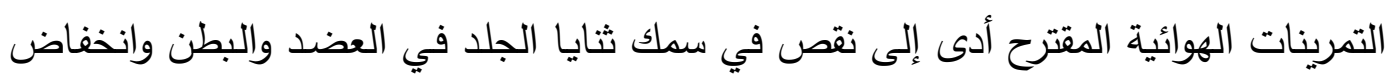

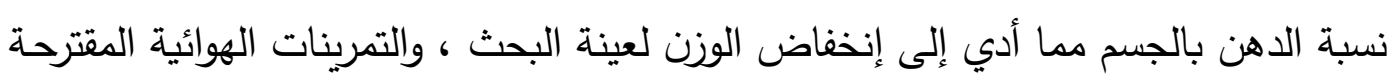

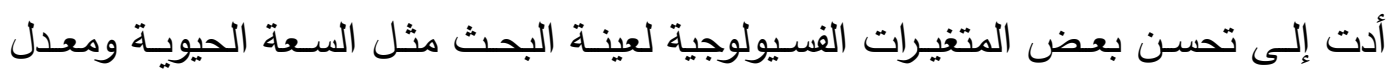

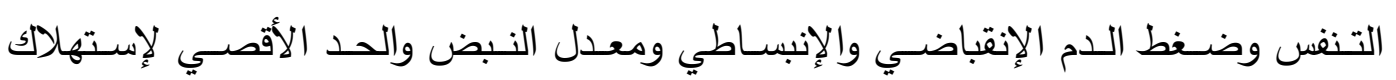

$$
\text { الأكسجين. (عايدة محمد) }
$$

الاستفادة من الاراسات السابقة:

تلقي الدراسات السابقة الضوء على كثير من المعالم التي تقيد الدراسة الحالية من خلال :

$$
\text { ا اختيار مجتمع الدراسة. العنمي المستخدم في الدراسة. }
$$

• اختيار افضل الاجهزة والادوات التي يمكن الحصول من خلالها على أدق النتائج •

$$
\text { كيفية اختيار تمرينات الكارديو المقترحة. }
$$

التعرف على أهم المعالجات الاحصائية المناسبة لطبيعة هذه الدراسة.

$$
\text { أولاً: منهاء الدات الدراسة: }
$$

استخدمت الباحثة المنهج التجريبي بتصميم المجموعتين التجريبية والضابطة نظراً لملاءمته

لطبيعة هذه الدراسة وأهدافها.

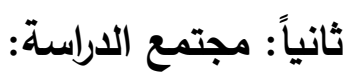

تكون مجتمع الدراسة من ممارسات اللياقة البدنية المنتسبين لمركز (بي إفكت) للياقة

البدنية البالغ عددهم (38) ممارسة والمسجلين في الكثوفات الرسمية للمركز . 
تكونت عينة الدراسة من (38) ممارسة ، تم تقسيمهم عشوائيا إلى مجموعتين إحدهما

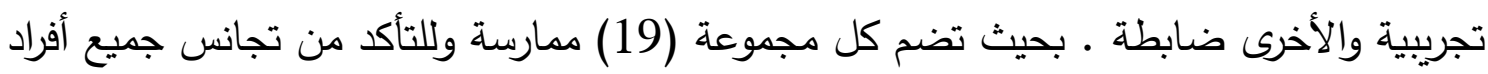
العينة في بيانات العمر والكتلة والطول ، ثم اجراء اختبار شيبرو (Shapiro- Wilk) حيث يوضح الجدول رقم (1) الوسط الحسابي والانحراف المعياري ، وقيمة Z ومستوي دلالتها. جدول (1)

الوسط الحسابي والانحراف المعياري وقيمة Z ومستوي دلالتها لاختبار (Shapiro - Wilk) لاعتدالية

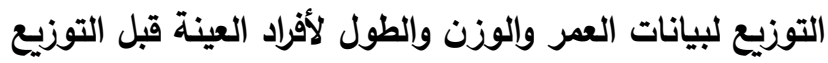
$38=$ ن

\begin{tabular}{|c|c|c|c|c|c|}
\hline$\alpha$ & ق قيمة Z & الاحراف المعرى & المتوسط الصلبي & وحة القيلس & المتغيرت \\
\hline 0.590 & $\overline{0.944}$ & 3.97 & 23.55 & سنة & العمر \\
\hline 0.196 & 0.960 & 4.73 & 74.13 & كجم & الوزن \\
\hline 0.217 & 0.962 & 6.39 & 164.60 & سم & الطول \\
\hline
\end{tabular}

يبين الجدول (1) قيم الوسط الحسابي والانحراف المعياري وقيمةZ لبيانات العمر والوزن والطول لأفراد عينة الدراسة قبل التوزيع، وعند إستعراض القيم الواردة في الجدول نجد أن متوسط العمر قد ولد

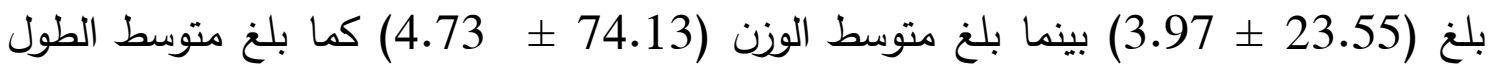

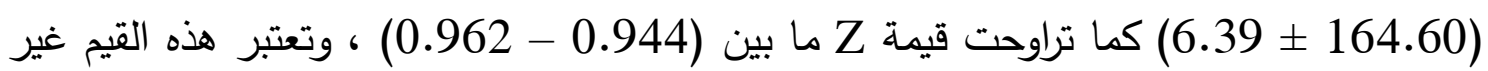
دالة إحصائياً ، مما يدل على اعتدالية توزيع بيانات هذه المتغيرات.

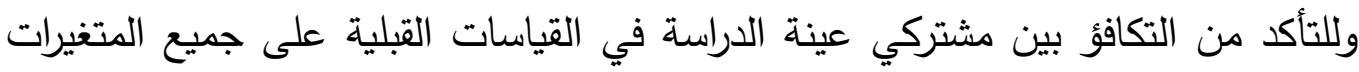
قيد الدراسة استخدمت الباحثة اختبار (Shapiro - Wilk) لاعتدالية التوزيع في جميع متغيرات الدراسة ونتائج الجدول رقم (2) توضح ذلك.

جدول(2) (2) (2)

الوسط الحسابي والانحراف المعياري وقيمة Z ومستوي دلالتها لاختبار (Shapiro - Wilk) لاعتدالية التوزيع في متغيرات الدراسة لأفراد العينة قبل التوزيع لالتيع التيع

$38=ن$

\begin{tabular}{|c|c|c|c|c|c|}
\hline A & قيمة Z & المعيارى & الحسابي & وحدة القياس & المتغيرات \\
\hline 0.255 & 0.874 & 611.76 & 4131.38 & كغنِ متّر/ & القارة اللااكسجينية \\
\hline 0.156 & 0.944 & 674.05 & 4022.12 & 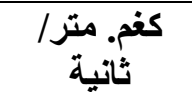 & السعة اللااكسجينية \\
\hline
\end{tabular}


المجلة العلمبة لعلوه وفنون الرإضة

\begin{tabular}{|c|c|c|c|c|c|}
\hline 0.663 & 0.971 & 7.09 & 38.36 & مللتر/كغم/ دقيقة & الحد الأقصي لإستهلاك الإكبين \\
\hline 0.973 & 0.884 & 2.56 & 24.35 & كفم/م2 & مؤشر كتلة الجسم \\
\hline 0.146 & 0.831 & 326.37 & 2042.36 & سعر / يوميا & معدل الأيض الأساسي \\
\hline 0.847 & 0.991 & 5.03 & 12.25 & $\%$ & كتلة الشحوم \\
\hline
\end{tabular}

دال إحصائياً عند مستوي (0.05 0 )

بالنظر إلى النتائج الواردة في الجدول (2) نجد أن قيمة مستوي الدلالة لجميع متغيرات الدراسة لأفراد عينة الدراسة قبل التوزيع أكبر من (0.05) ، مما يعني عدم وجود فروق ذات دلالة احصائية عند مستوي الدلالة (0.05>0) بين أفراد عينة الدراسة في القياس القبلي ، على جميع متغيرات الدراسة مما يدل على تجانس افراد عينة الدراسة في القياس القبلي ثم قامت الباحثة بتقسيم العينة عشوائيا إلى مجموعتين ، مجموعة تجريبية تخضع لبرنامج مقترح من تمرينات الكارديو وأخري ضابطة وبواقع (19) فرداً لكل مجموعة. رابعاً: ادوات الدراسة:

قامت الباحثة بتصميم استمارة لتسجيل المعلومات الشخصية ونتائج الاختبارات والقياسات

للمشتركين كما هو موضح في مرفق (1) • واستخدمت الباحثة ميزان طبي من نوع سيجا(SECA) لقياس الوزن ، كما استخدمت الرستاميتر لقياس الطول ، وهو عبارة عن قائم مثبت بشكل عمودي على قاعدة خشبية تقف عليها المشتركة ويمتد طول القائم إلى 250 سم ، بحيث يكون الصفر مستوي القاعدة الخشبية ، ولقياس متغيرات الدراسة استخدمت الباحثة الاختبارات التالية:

1- اختبار القدرة والسعة اللأكسجينية:

استخدمت الباحثة إختبار الخطوة لآدمز (Adams, 1990) باستخدام الصندوق الخشبي ،

لمدة (15) و (60) ث ، وقد استخدمت الباحثة في هذا الاختبار الأدوات التالية: - صندوق خشبي للخطوة ارتفاعه (40) سم.

- - ماعة ايقاف لها مؤشر الثواني.

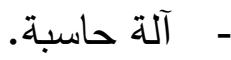
- - - استمارة لتسجيل البيانات والنتائج. ومرفق رقم (2) يوضح وصف الاختبار • 2- الحد الأقصي لإستهلاك الأكسجين النسبي Vo2 Max: 
استخدمت الباحثة إختبار الجري (12) دقيقة لكوبر لقياس الحد الأقصي لإستهلالك الأكسجين النسبي Vo - ساعة إيقاف.

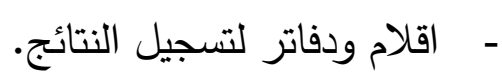
-

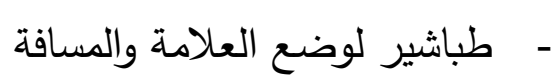
ومرفق رقم (3) يوضح وصف الاختبار وطريقة الاستخدام والقياس.

3- جهاز التانيتا (TANITA)

إستخدمت الباحثة جهاز التانيتا لقياس تحليل تركيب الجسم ويتضمن الدهون، ومؤشر كتلة الجسم

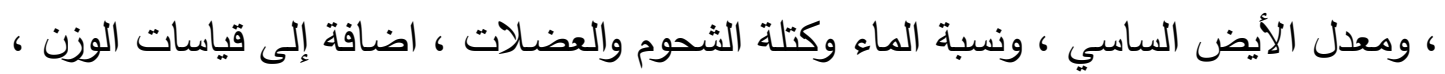

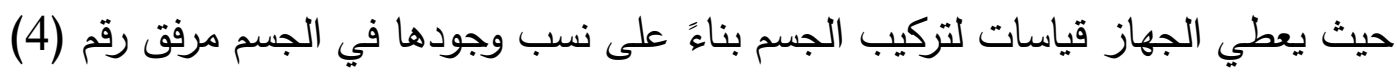
يوضح وصف الاختبار وطريقة الاستخدام والقياس. كما استخدمت الباحثة في البرنامج التدريبي الأدوات التالية:

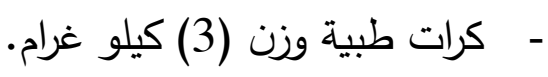

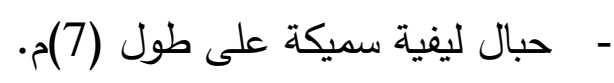
- - بار حديدي عدد (9). - -

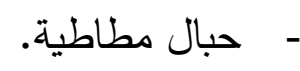

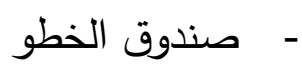
- ساعة ايقاف CD -

خامساً: المعاملات العلمية لأدوات الدراسة:

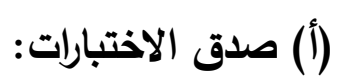

حقق اختبار الخطوة لآدمز ( Adams, 1990المستخدم لقياس كل من القدرة والسعة

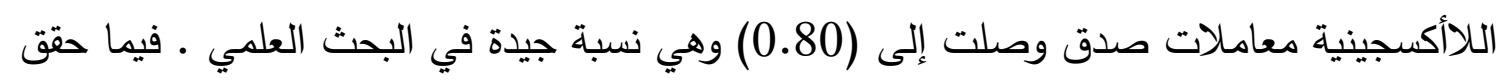


اختبار الحد القصي لإستهلاك الأكسجين النسبي باستخدام اختبار كوبر (جري 12 دقيقة) معاملات صدق وصلت عند ( Pener et al., 2011) (0.96) وهي نسبة مرتفعة. وفيما يتعلق بجهاز التانيتا الذي تم استخدامه لقياس معدل الأيض الأساسي ، وكتلة الشحوم ، ومؤشر كتلة الجسم ، فقد حقق الجهاز معاملات صدق وصلت عند ( Metcalfe \& Kelly, 2012 (إلى

$$
\begin{aligned}
& \text { (0.81) وهي نسبة جيدة في البحث العلمي. } \\
& \text { (ب) ثبات الاختبارات }
\end{aligned}
$$

لحساب ثبات الاختبارات ، قامت الباحثة بإستخدام طريقة تطبيق الاختبار وإعادة تطبيقه Test Retest) ) ، وقد تم حساب معامل ارتباط بيرسون والجدول رقم (3) يوضح معاملات الثبات للمتغيرات قيد الدراسة.

جدول (3)

نتائج معامل ارتباط بيرسون لثبات الاختبارات قيد الدراسة

\begin{tabular}{|c|c|c|c|c|c|c|c|}
\hline \multirow{2}{*}{ الدلالة } & \multirow{2}{*}{ قيمة } & \multicolumn{2}{|c|}{$\begin{array}{l}\text { القياس الثاني } \\
5=0\end{array}$} & \multicolumn{2}{|c|}{$\begin{array}{c}\text { القياس الأول } 5= \\
5=0\end{array}$} & \multirow{2}{*}{ وحدة القياس } & \multirow{2}{*}{ المتغير ات } \\
\hline & & الانحراف & الحسبابي المتوسط & الانحريارى & المستوسطي & & \\
\hline 0.013 & 0.95 & 689.15 & 4188.96 & 747.73 & 4152.16 & كفم. متر/ & القدرة اللاأكسجينية \\
\hline 0.006 & 0.87 & 513.81 & 4218.81 & 566.26 & 4105.40 & كفنم. متر/ & السعة اللاأكسجينية \\
\hline 0.022 & 0.92 & 6.81 & 36.77 & 8.14 & 35.86 & مللتز/كغم/ & الاكد الأقصي لإستهلاك النسبي \\
\hline 0.009 & 0.94 & 3.83 & 23.98 & 3.79 & 23.48 & كفم/م2 & مؤشر كتلة الجسم \\
\hline 0.015 & 0.89 & 277.28 & 2061.17 & 266.32 & 2198.00 & سعر / يوميا & معدل الأيض الأساسي \\
\hline 0.001 & 0.84 & 6.70 & 10.52 & 6.42 & 10.50 & $\%$ & كتلة الشحوم \\
\hline
\end{tabular}

$(5=\dot{0})$

aت م) من من الجدول (3) أن جميع معاملات الارتباط ذات دلالة احصائية عند مستوي الدلالة

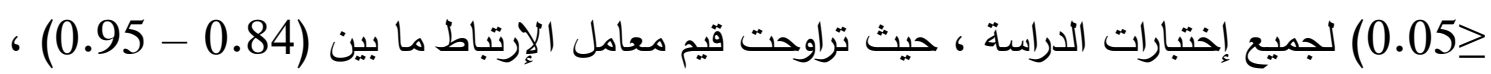
وفى ذلك اشارة إلى أن جميع إختبارات الدراسة تتمتع بدرجة عالية من الثبات. سادساً: الاراسة الاستطلاعية: 
قامت الباحثة بتطبيق (3) وحدات تدريبية من البرنامج التدربي على عينة مكونة من (5) افراد تم إختيارهم بطريقة عمدية من مجتمع الدراسة الأصلي ، وذلك بغرض التأكد من مدي صلاحية ومناسبة مكان إجراء الدراسة ، وكذلك التعرف على المدة الزمنية التي يستغرقها اداء الوحدة التدريبية ، والمدة الزمنية التي يستغرقها اداء جزء من اجزاء الوحدة التدربيية ووضع الثدة والحجم المناسبين لكل تمرين ، بالإضافة إلى التعرف على الصعوبات التي يمكن أن تواجهها الباحثة أثناء تطبيق البرنامج التدربي ، واثناء أداء الاختبارات ، إضافة للتأكد من ثبات الأدوات المستخدمة في الدراسة.

وبعد الانتهاء من الدراسة الإستطلاعية توصلت الباحثة إلى :

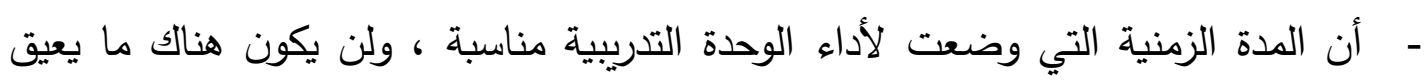
إتمام الوحدة التدريبية في وقتها المحدد. - - أن جميع التمرينات التي اختارتها الباحثة مناسبة ، ومن الممكن اداؤها بثدة وحجم مناسبين لأفراد عينة الدراسة.

سابعاً: خطوات تنفيذ الاراسةة: أجريت هذه الدراسة وفق المراحل التالية: أ- مرحلة ما قبل القياس. ب- مرحلة القياس القبلي. ج- مرحلة القياس البعدي. وفيما يلي توضح ذلك: (أ) مرحلة ما قبل القياس:

في هذه المرحلة قامت الباحثة بإجراء مايلي: 1- قامت الباحثة بإختيار الممارسات اللاتي سيكونن ضمن عينة الدراسة ، وهن عبارة عن الممارسات المنتسبين إلى مركز ( بي افكت ) للياقة البدنية، وتأكدت الباحثة من رغبة هؤلاء الممارسات في الاشتراك بالدراسة.

2- تصميم استمارة تسجيل خاصة بالمشتركات بحيث تشمل القياسات المطلوبة. 3- قامت الباحثة بمخاطبة مركز ( بي إفكت ) للياقة البدنية وذلك من أجل الموافقة على إستخدام صالة المركز ، ويوضح ذلك مرفق رقم (5). 4- قامت الباحثة بمخاطبة المركز الصحي من أجل استخدام جهاز التانيتا (TANITA) لإجراء القياسات القبلية والبعدية ومرفق رقم (6) يوضح ذلك. 
تم إجراء القياس القبلي للمجموعتين التجريبية والضابطة وذلك بعد اجراء الدراسة الإستطلاعية ، وقد تم اجراء القياسات في يومين مختلفين ، حيث تم اجراء الإختبارات القبلية للمجموعة التجريبية

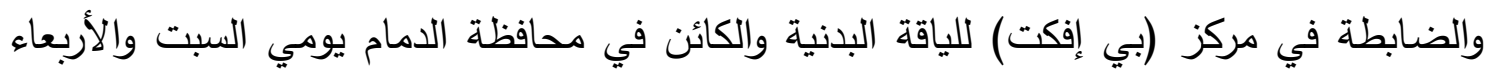

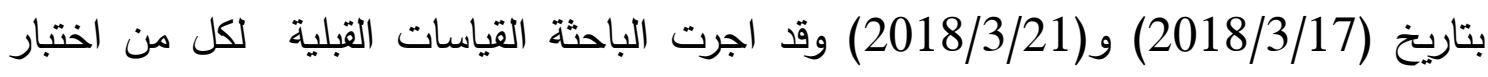

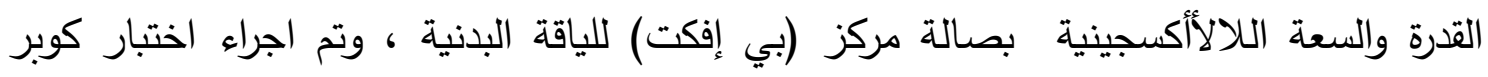
(12) دقيقة لقياس الحد الأقصي لإستهلاك الأكجسين النسبي (Vo2 Max) في ملعب بإحدي الإستراحات الخاصة والتي تجاور مركز (بي إفكت) للياقة البدنية ، وقد تم إجراء إختبار تحليل تركيب الجسم بمختبر المركز الصحي بالدمام .

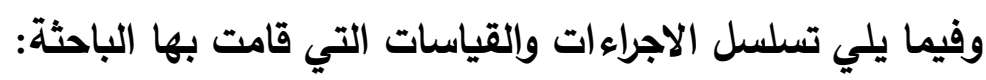
1 - تعبئة البيانات الثخصية للمشتركات (الاسم ، العمر). 2- - اجراء قياسات الوزن والطول لعينة الدراسة.

3- قبل البدء بإجراء الإختبارات البدنية ، قامت الباحثة بشرح خطوات إجراء الإختبارات

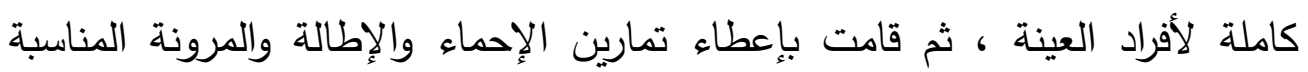

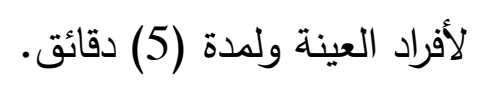

4- بدأت الباحثة بإجراء الإختبار القبلي لأفراد عينة الدراسة المتعلقة بالقدرة والسعة

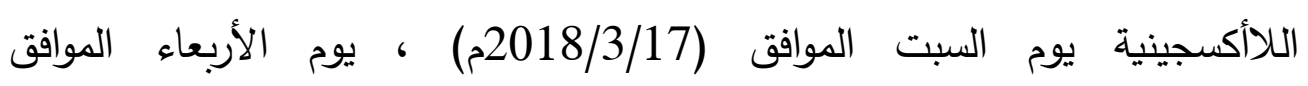
(2018/3/21م) أجرت الباحثة إختبار تانيتا TANITA في في المركز الصحي الصيات بالدمام صباحاً ، ثم اختبار الجري (12) دقيقة لكوبر - ملعب استراحة خاصة مساءً.

\section{البرنامج التدريبي:}

قامت الباحثة بإعداد برنامج يشمل مجموعة من تمرينات الكارديو وذلك بعد الاطلاع على المراجع

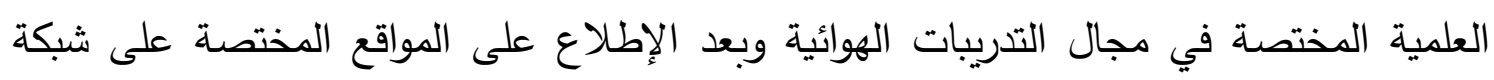
المعلومات الدولية.

قامت الباحثة بإعداد البرنامج التدريبي بحيث راعت في إعداده مبادئ وأسس فسيولوجيا التدريب بالإضافة إلى مراعاة نوعية التمرينات المستخدمة بحيث تعمل على تنمية المتغيرات الفسيولوجية والبدنية قيد الدراسة.

قامت الباحثة بتطبيق البرنامج التدريبي المقترح على المجموعة التجريبية بحيث تم تدريبهم عليه في الفترة الزمنية المسائية ما بين الساعة (5:30- 7:00) لكل وحدة تدريبية في صالة (بي إفكت) 
للياقة البدنية ، وبواقع (4) وحدات أسبوعية زمن الوحدة بدأ من (45)ق وتدرج حتى نهاية البرنامج

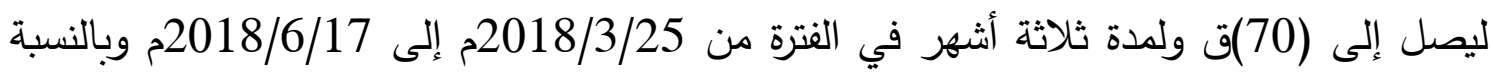
للمجموعة الضابطة فقد خضعت لبرنامجها التدريبي الأيروبيك الإعتيادي التقليدي وبنفس الوقت وقد تم مراعاة النقاط التالية: 1- الإحماء دائما قبل البدء بالجزء الرئيسي.

2- قامت الباحثة بتحديد شدة التدريب والنبض المتوقع أثناء التدريب بإستخدام النسب المئوية التباء لأقصي نبض ، من خلال النتائج التي حصلت عليها في التجربة الإستطلاعية.

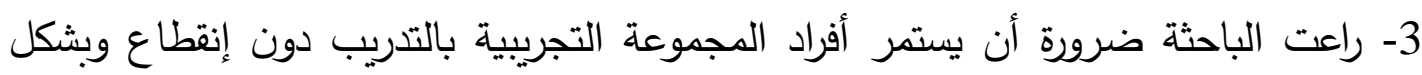
منتظم طوال فترة تطبيق البرنامج. 4- تمثلت خصوصية التدريب في هذا البرنامج بخصوصية التمرينات ، التي كانت موجهة

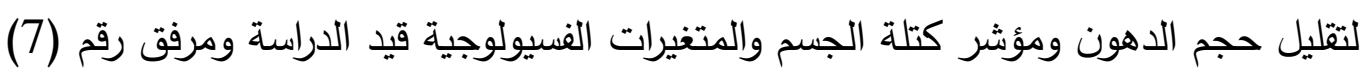
يوضح محتوي البرنامج.

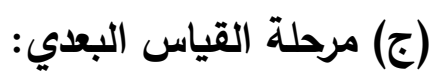
بعد الإنتهاء من تطبيق البرنامج التدريبي ، تم إجراء كافة الإختبارات والقياسات البعدية في

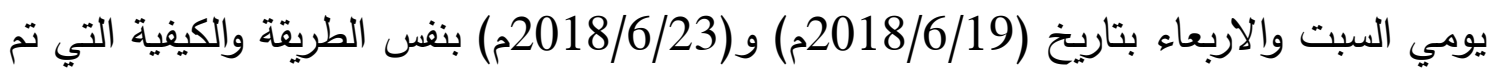
بها إجراء الإختبارات والقياسات القبلية. متغيرات الدراسة: أولاً: المتغير المستقل ويشتمل على: - برنامج مقترح لتمرينات الكارديو . ثانياً: المتفيرات التابعة وهي:

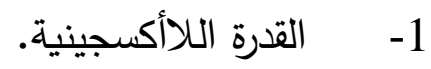
2- - - السعة اللاأكسجينية. 3- - الحد الأقصي لإستهلاك الاكسجين النسبي.

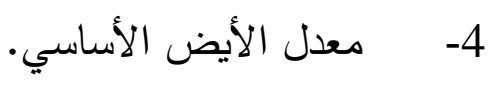
56- مؤشر كتلة الجسم. المعالجات الإحصائية المستخدمة: 
من أجل تحقيق أهداف الدراسة والإجابة عن تساؤلاتها استخدمت الباحثة المعالجات الإحصائية الآتية: - n

$$
\text { 1- المتوسطات الحسابية والإنحرافات المعيارية ونسب التحسن. }
$$

2- اختبار "شبيرو ويلك" (Wilk Shapiro) للتأكد من التكافؤ بين أفراد عينة الدراسة. 3- استخدمت الباحثة إختبار (ت) للعينات غير المستقلة - Paired Samples T ) ، لدلالة الفروق بين القياسين القبلي والبعدي للمجموعتين التجريبية والضابطة Test)

$$
\text { وعلى كافة المتغيرات قيد الدراسة. }
$$

4- اختبار (ت) للعينات المستقلة (Independent Samples T-Test) لدلالة الفروق بين القياس البعدي للمجموعتين التجرببية والضابطة ، وعلى كافة المتغيرات قيد

$$
\text { (أ) كامناً: عرض نتائج الدراسة ومناقشتها: }
$$

يثير التساؤل الأول والذي ينص على : " هل توجد فروق ذات دلالة إحصائية بين القياسين القبلي والبعدي في متغيرات الدراسة الفسيولوجية (حجم الدهون ، مؤشر كتلة الجسم ، القدرة اللألكسيجينة ، السعة اللاأكسجينية ، الحد الأقصي لإستهلاك الأكسجين النسبي) لاي أفراد

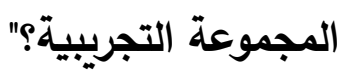

\begin{tabular}{|c|c|c|c|c|c|c|c|}
\hline \multirow{2}{*}{ مستوي الدلاكي } & \multirow[t]{2}{*}{ قيمة T } & \multicolumn{2}{|c|}{ القياس البعدي } & \multicolumn{2}{|c|}{ القياس القبلي } & \multirow[t]{2}{*}{ وحدة القياس } & \multirow[t]{2}{*}{ المتغيرات } \\
\hline & & الاتحر اف & المتوسط & الانحر اف & المتوسط & & \\
\hline
\end{tabular}
Paired Samples ) ولإجابة عن هذا التساؤل إستخدمت الباحثة اختبار (ت) للأزواج المرتبطة ك-Test) للمجموعة التجريبية ، وذلك كما هو موضح في جدول رقم (4). جدول (4)

بين القياس القبلي والبعدى لأفراد (Paired Samples T-Test)تتائج اختبار (ت) للأزواج المرتبطة المجموعة التجريبية على المتغيرات الفسيولوجية $(19=\dot{0})$ 


\begin{tabular}{|c|c|c|c|c|c|c|c|}
\hline & & المعيارى & الحسابي & المعيارى & الحسابي & & \\
\hline $0.000 *$ & 11.50 & 889.08 & 5596.91 & 611.76 & 4131.38 & كفُنه. متزر/ & القرة اللاأكسجينية \\
\hline $0.000 *$ & 8.82 & 625.56 & 4971 & 674.05 & 4022.12 & كفنم. متر/ & السعة اللاأكسجينية \\
\hline $0.000 *$ & 7.90 & 5.37 & 46.01 & 7.09 & 38.36 & مللتر/كغم/ دقية & الحد الأقصي لإستهلاك النسبي \\
\hline 0.421 & 3.28 & 2.36 & 24.77 & 2.56 & 24.35 & كغم/ק2 & مؤشر كتلة الجسم \\
\hline 0.475 & 0.730 & 245.37 & 1971.21 & 326.37 & 2042.36 & سعر / يوميا & معدل الأيض الأساسي \\
\hline 0.601 & 0.532 & 4.70 & 12.44 & 5.03 & 12.25 & $\%$ & كتلة الشحوم \\
\hline
\end{tabular}

دال إحصائياً عند مستوي (0.05 (0. )

ويبين الجدول (4) قيمة T المحسوبة ومستوي دلالتها والمتوسط الحسابي والإنحراف المعياري لمجموع متغيرات الدراسة على القياسين القبلي والبعدي لأفراد المجموعة التجريبية ـ وبالنظر إلى والى دالى

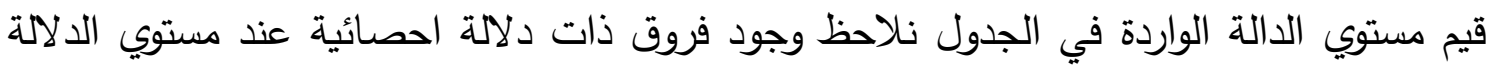

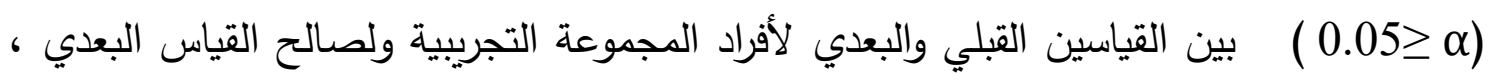

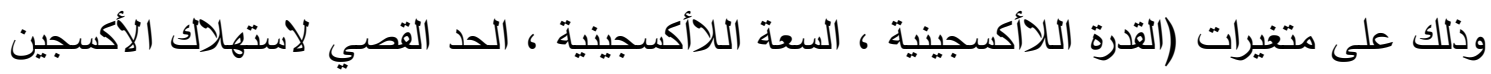
النسبي) ، حيث كانت قيم مستوي الدلالة على التوالي كالآتي (0.000 ، 0.000 ، 0.000، 0.000 ، 0.00

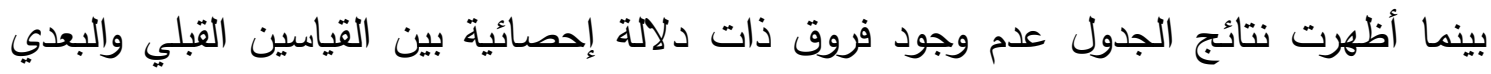

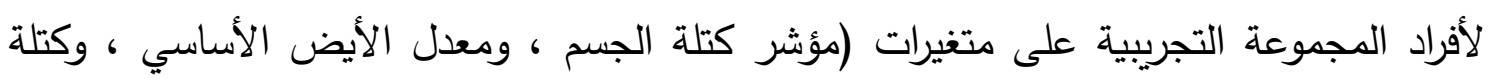
الثحوم).

وللتعرف على الفروق بين القياسين القبلي والبعدي لأفراد المجموعة التجريبية ، قامت الباحثة

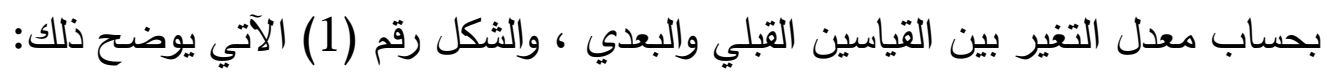

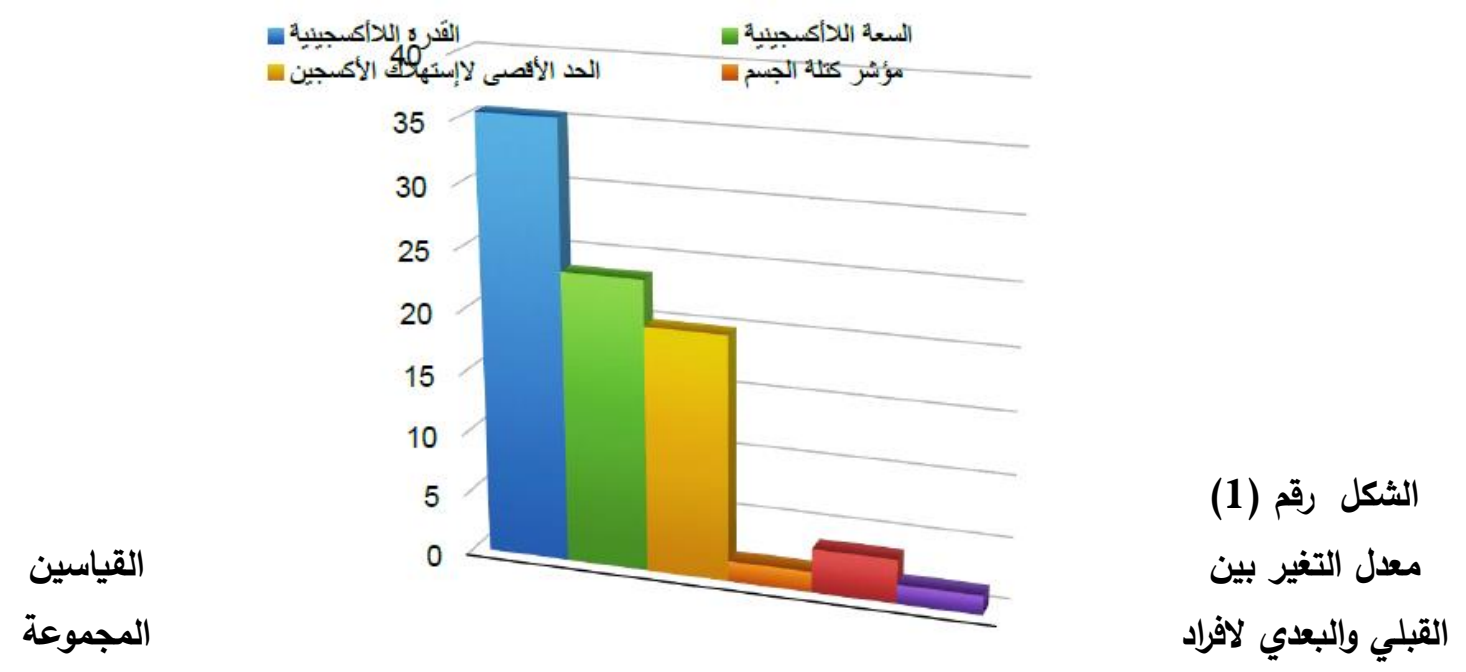




\section{التجريبية على جميع متغيرات الدراسة}

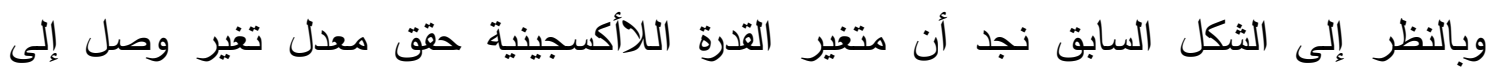

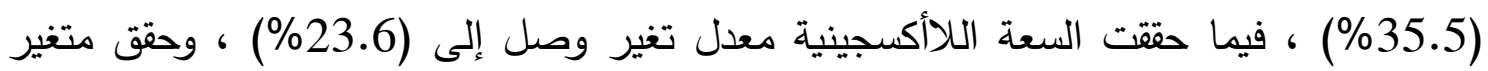
الحد الأقصي لإستهلاك الأكسجين النسبي معدل تغير وصل إلى (19.9\%) بينما حقق متغير مؤشر كتلة الجسم معدل تغير وصل إلى (1.7\%) ، وحقق متغير معدل الأيض الأساسي معدل

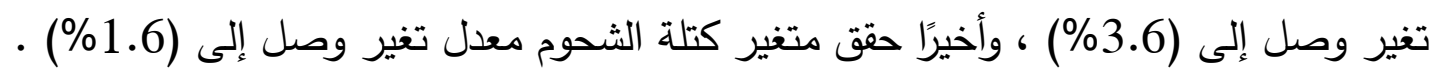
نتائج التساؤل الثاني:

يشير التساؤل الثاني والذي ينص على : " هل توجد فروق ذات دلالة إحصائية بين القياسين

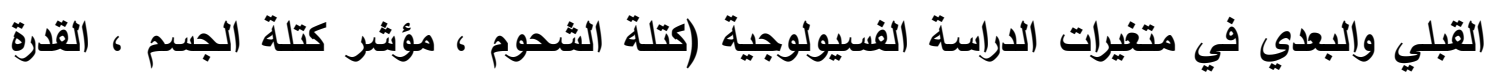
اللاأكسيجينية، السعة اللاأكسينية ، الحد الأقصي لاستهلاك الأكسجين النسبي) لائي أفراد

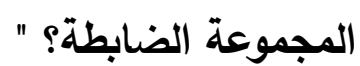

وللتعرف على دلالة الفروق بين القياسين القبلي والبعدي لمتغيرات الدراسة الفسيولوجية للمجموعة الضابطة ، وللاجابة عن التساؤل الثاني إستخدمت الباحثة إختبار (ت) للأزواج المرتبطة (Paired Samples T-Test) وذلك كما هو موضح في الجدول رقم (5) الآتي:

\section{جدول (5)}

بين القياس القبلي والبعدى لأفراد (Paired Samples T-Test)نتائج اختبار (ت) للأزواج المرتبطة المجموعة الضابطة على المتغيرات الفسيولوجية

$(19=0)$

\begin{tabular}{|c|c|c|c|c|c|c|c|}
\hline \multirow{2}{*}{ مستول } & \multirow{2}{*}{ قيمة T } & \multicolumn{2}{|c|}{ القياس البعدي 19} & \multicolumn{2}{|c|}{ 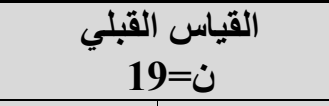 } & \multirow{2}{*}{ القياس } & \multirow{2}{*}{ المتغيرات } \\
\hline & & المعيارى & الحستوسي & المعيارى & الحسابي & & \\
\hline 0.953 & 0.060 & $\mathbf{7 3 4 . 8 2}$ & 3889.16 & 653.84 & 3983.51 & كفنم. متّر/ & القدرة اللاأكسجينية \\
\hline 0.114 & $1.66-$ & 767.09 & 3849.03 & 675.66 & 3710.85 & كفنْه متر/ & السعة اللاأكسجينية \\
\hline 0.721 & $0.362-$ & 6.77 & 39.43 & 6.49 & 39.33 & مللتر/كفم/ & لإستهلاك الاكجسين \\
\hline 0.056 & $2.044-$ & 5.63 & 24.47 & 5.49 & 24.30 & كغم/م2 & مؤشر كتلة الجسم \\
\hline 0.059 & $4.254-$ & 272.52 & 1943.26 & 269.32 & 1898.26 & سعر / يوميا & معدل الأيض \\
\hline
\end{tabular}




\begin{tabular}{|c|c|c|c|c|c|c|c|}
\hline 0.054 & $2.061-$ & 7.57 & 12.79 & 7.43 & 12.65 & $\%$ & كتلة الشحوم \\
\hline
\end{tabular}

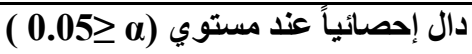

ويبين الجدول (5) قيمة T المحسوبة ومستوي دلالتها والمتوسط الحسابي والانحراف المعياري لمجموع متغيرات الدراسة على القياسين القبلي والبعدي لأفراد المجموعة الضابطة. وبالنظر إلى القيم الواردة في الجدول نجد أن عدم وجود فروق ذات دلالة احصائية عند مستوي الدلالة)

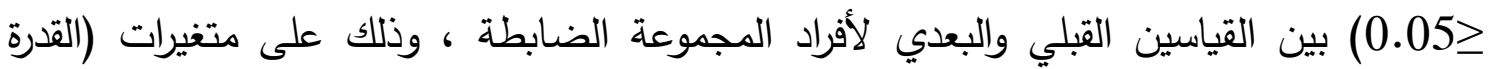
اللأكسجينية ، والسعة اللأكسجينية ، الحد القصي لاستهلاك الأكسجين النسبي ، ومؤشر كتلة الجسم ، ومعدل الأيض الأساسي ، وكتلة الثحوم) ، حيث كانت قيمة مستوي الدلالة أكبر من (0.05). نتائج التساؤل الثالث: يثير التساؤل الثالث والذي ينص على : " هل توجد فروق ذات دلالة إحصائية بين افراد المجموعتين التجريبية والضابطة في القياس البعدي على جميع متغيرات الدراسة الفسيولوجية (كتلة الشحوم ، مؤشر كتلة الجسم ، القدرة اللالأكسيجينة ، السعة اللاأكسجينية ، الحد الأقصي

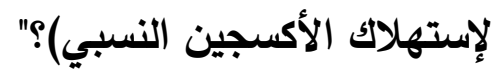
ولإجابة عن هذا التساؤل استخدمت الباحثة اختبار (ت) لالالة الفروق بين مجموعتين مستقلتين (Independent Samples T-Test)

\section{جدول (6)}

نتائج اختبار (ت) لدلالة الفروق بين مجموعتين مستقلتين (Independent Samples T-Test) لإيجاد الفروق بين أفراد المجموعة التجرببية والضابطة في القياس البعدي على جميع متغيرات الدرسة $(38=ن)$

\begin{tabular}{|c|c|c|c|c|c|c|c|}
\hline \multirow{2}{*}{ الدالاية } & \multirow{2}{*}{ قيمة T } & \multicolumn{2}{|c|}{ المجموعة الضابطة } & \multicolumn{2}{|c|}{ المجموعة التجريبية } & \multirow{2}{*}{ وحدة القياس } & \multirow{2}{*}{ المتغيرات } \\
\hline & & الالمعراف & الحسابي & الانحريارى & الحسابي & & \\
\hline $0.000 *$ & 6.45 & 734.82 & 3889.16 & 889.08 & 5596.91 & كفنم. متر/ & القدرة اللاأكسجينية \\
\hline $0.000 *$ & 4.94 & 767.09 & 3849.03 & 625.56 & 4971.00 & كغن. متزل/ & السعة اللاأكسجينية \\
\hline $0.002 *$ & 3.31 & 6.77 & 39.43 & 5.37 & 46.01 & مللتر/كغم/ & الإكستهلاكين النسبي \\
\hline 0.832 & 0.214 & 5.63 & 24.47 & 2.36 & 24.77 & كفم/م2 & مؤشر كتلة الجسم \\
\hline
\end{tabular}




\begin{tabular}{|c|c|c|c|c|c|c|c|}
\hline 0.742 & 0.332 & 272.52 & 1943.26 & 245.37 & 1971.21 & سعر / يوميا & معدل الأيض الأساسي \\
\hline 0.867 & $1.68-$ & 7.57 & 12.79 & 4.70 & 12.44 & $\%$ & كتبة الشحوم \\
\hline
\end{tabular}

(1) 0.05

وبالنظر إلى قيم مستوي الدلالة في الجدول (6) يتضح وجود فروق ذات دلالة احصائية عند مستوي الدلالة (0.05 (0.0) في القياسين البعديين لأفراد المجموعة التجربيية والضابطة ، ولصالح المجموعة التجرببية في متغيرات (القدرة اللأكسجينية ، السعة اللأكسجينية ، الحد القصي لإستهلاك الأكسجين النسبي) ، كما تشير نتائج الجدول (6) إلى عدم وجود فروق ذات دلالة إحصائية بين أفراد المجموعة التجريبية والضابطة في متغيرات ( مؤشر كتلة الجسم ، ومعدل الأيض الأساسي ، وكتلة الثحوم). (ب) مناقثة النتائج: مناقشة النتائج المتعلقة بالتساؤل الأول والذي ينص على: "هل توجد فروق ذات دلالة إحصائية بين القياسين القبلي والبعدي في متغيرات الدراسة الفسيولوجية (كتلة الشحوم ، مؤشر كتلة م ، القدرة اللاأكسجينية ، السعة اللاأكسجينية ، الحد الأقصي لإستهلاك الأكسجين النسبي

) ، لاى أفراد المجموعة التجريبية؟"

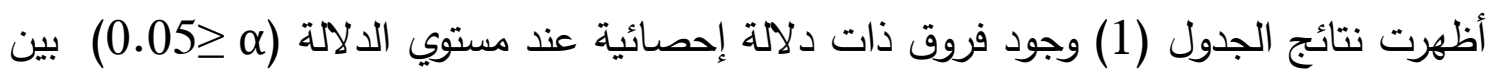
القياسين القبلي والبعدي لأفراد المجموعة التجريبية و لصالح القياس البعدي ، وذلك على متغيرات (القدرة اللأكسينية ، السعة اللأكسجينية ، الحد القصي لإستهلاك الأكسجين النسبي) ، حيث حقق متغير القدرة اللأكسجينية نسبة تغير مئوية وصلت إلى (35.5\%) ، فيما حقتت السعة

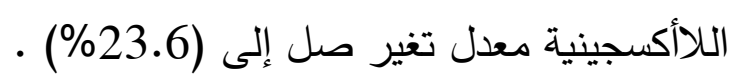
وتعزو الباحثة السبب المباشر في هذا التحسن في القدرة اللأكسجينية إلى طبيعة التمرينات المستخدمة في البرنامج التدربي ، حيث احتوي البرنامج على مجموعة من تمرينات الكارديو ذات الثدة العالية ولفترات زمنية متدرجة ، حيث تؤدي مثل هذه التمرينات إلى زيادة مخزون العضلات من مركبات الطاقة ، مثل ثلاثي ادينوزين الفوسفات (ATP) بالإضافة إلى فوسفات الكرياتين (PC)

اللأكسجينية.

حيث أشار" ماني" (Mannei, 2004) إلى أن التمرينات ذات الثدة العالية تؤدي إلى زيادة سرعة وفاعلية عمليات انتاج الطاقة ، وانها الطريقة الأكثر فعالية لتتمية العمل اللأكسجيني، ويأتي ذلك بسبب زيادة مخزون أدينوسين ثلاثي الفوسفات (ATP) في العضلات ، ومخزون فوسفات 
الكرياتين (PC) ، بالإضافة إلى الزيادة في نثاط الانزيمات المساعدة في التفاعلات الكيميائية وانتاج الطاقة ، مثل انزيم (PTPASE) ، وإنزيم الكرياتين فسفوكاينيز (CRK-Creatine) حيث تؤدي الزيادة في نشاط الإنزيمات مع الزيادة في مخزون الطاقة في

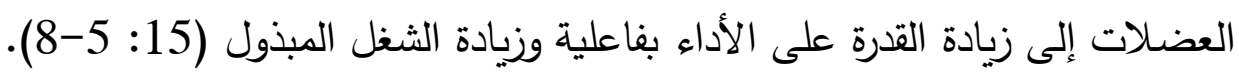

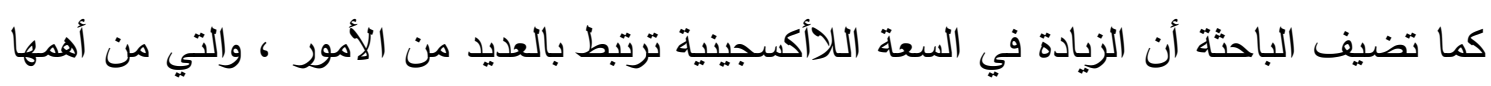

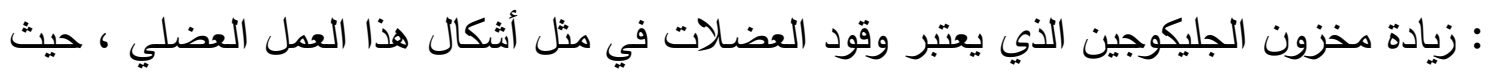

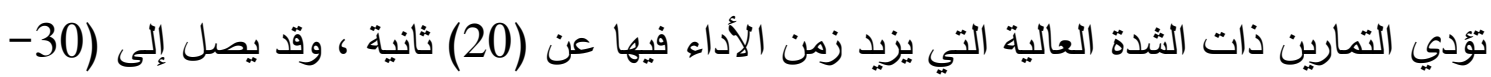

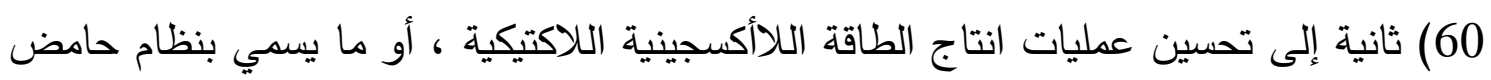

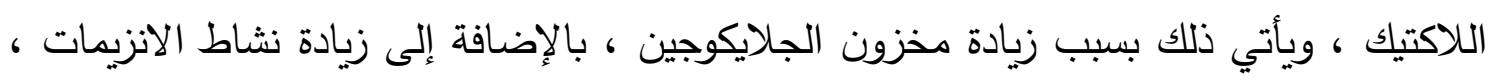

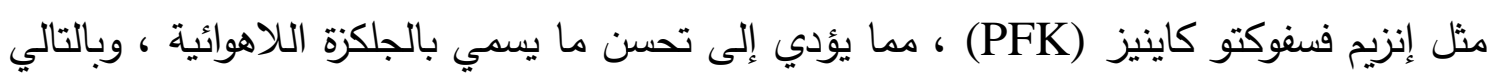

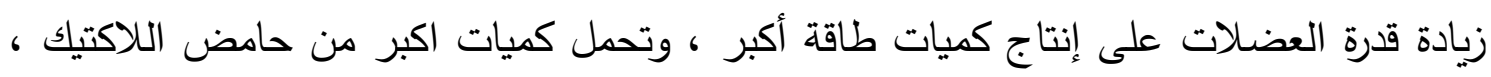

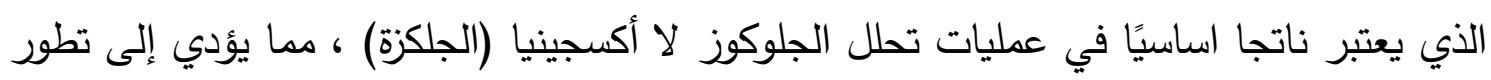
السعة اللاأكسينية التي تعتمد بثكل اساسي على كفاءة علميات الجلكزة اللاأكسجينية في انتاج الطاقة.

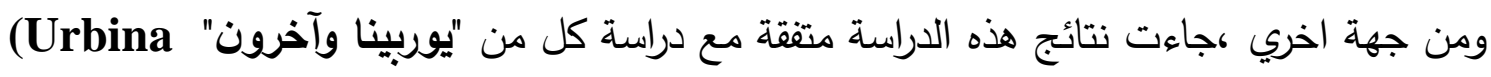

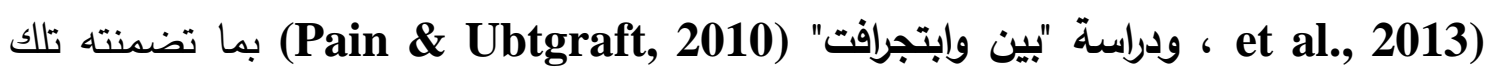
الدراسات من إستخدام لتمارين مشابهة للدراسة الحالية ، والتي اشارت إلى زيادة القدرة على الأداء

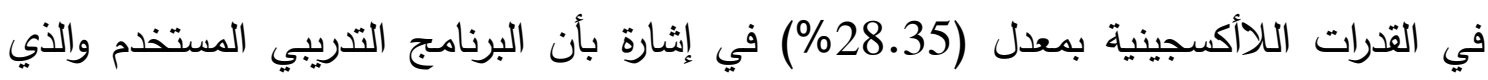

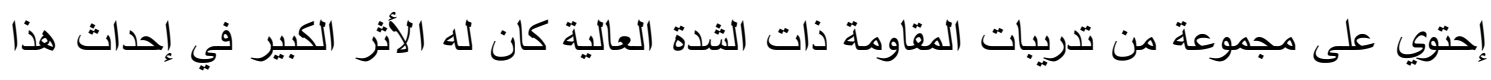

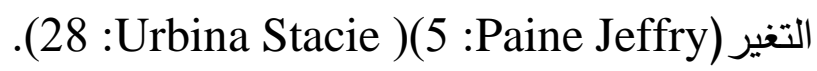

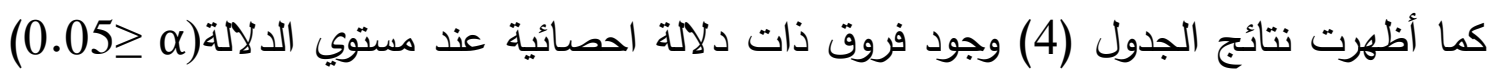

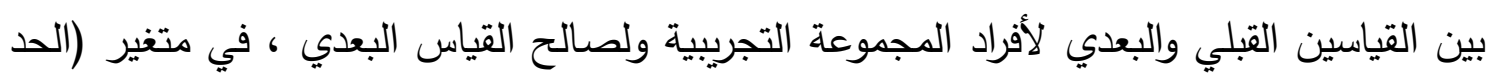

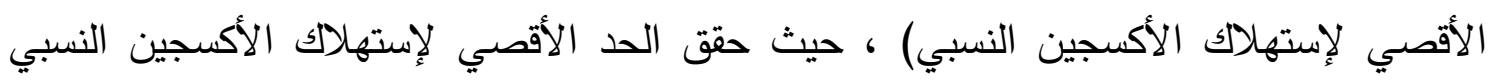
معدل تغير وصل إلى (19.9\%).

وتعزو الباحثة هذا التحسن في الحد الأقصي لإستهلاك الاكسجين النسبي ، إلى طبيعة المجهود

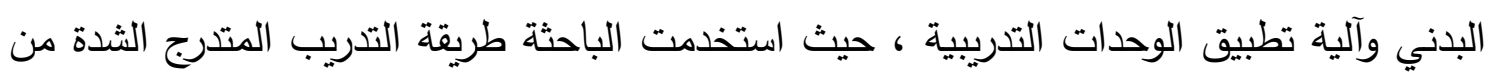

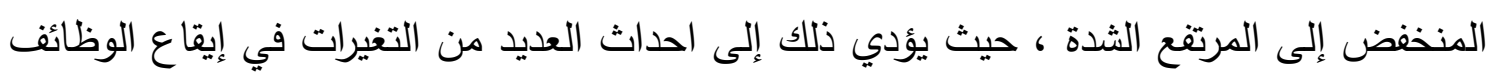

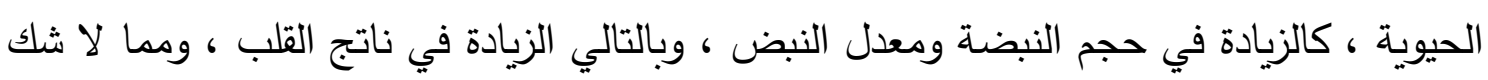


في أن الزيادة في معدل ضربات القلب وناتج القلب يؤدي إلى الزيادة في الحد الأقصي لإستهلاك الأكسجين النسبي ، حيث يشير" لوناتا وآخرون" (Lounana \& et al., 2007) إلى أن الزيادة في معدل ضربات القلب يعتبر مؤشراً بنسبة (85\%) للتنبؤ بالزيادة في معدل الحد الأقصي لاستهلاك الاكسجين النسبي (Lounana: 350) وتأتي الزيادة في معدل ضربات القلب وناتج القلب بسبب الزيادة في الطلب على الأكسجين من قبل خلايا العضلات العاملة ، وبالتالي زيادة كمية الاكسجين الواصلة للعضلات العاملة من خلال زيادة حجم التهوية الرئوية ، حيث تؤدي زيادة الحمل البدني الواقع على العضلات إلى زيادة درجة حرارتها الموضعية ، وبالتالي زيادة تركيز أيون الهيدروجين في العضلات ، وبالتالي زيادة كمية الأكسجين التي تمتصها أو تستهكها الخلايا العضلية ، حيث يؤكد "جورملي وآخرون" أن الأشكال المختلفة من التدريبات مرتقعة الثدة وذات الأحجام (Gormaley et al., 2008) العالية تؤدي إلى الزيادة في الحد الأقصي لإستهلاك الأكسجين النسبي بنسبة متفاوتة (40:Gormley)

وتعتبر الزيادة في إستهلاك الأكسجين مؤشراً للزيادة في عمليات الأكسدة وإنتاج الطاقة أكسجينيا ، ويأتي ذلك بسبب الزيادة في عمليات أكسدة الجلايكوجين وأكسده الأحماض الدهنية الحرة في حلقة كربس ، كما تأتي أيضاً بسبب الزيادة في نشاط أهم إنزيمات حلقة كريس مثل انزيم "سكسنت ديهروجينيز" (DDH) (Dehydrogenase Succinate) ، حيث يؤكد "كرافتس وداليك" حمريك أن الزيادة في حجم التدريب له فعالية كبري في تحسين (Kravijs \& Dalleck, 2008) الأنزيمات المساعدة في التنفس الخلوي للمايتوكندريا وبالتالي تحسين عمليات الأكسدة ) Len .(19-4 :Kravits وتتفق تلك النتائج مع ما اشار اليه " لارسون" (Larson, 2015) أن التدريب المتدرج والمرتفع الثدة بتنوع أساليبه الأكسجينية واللأكسجينية يمكن أن يستخدم لتطوير مستوي عالٍ جداً من اللياقة البدنية الأكسجينية ، حيث يزيد من معدل استهلاك الأكسجين مع زيادة شدة التمرين لفترة

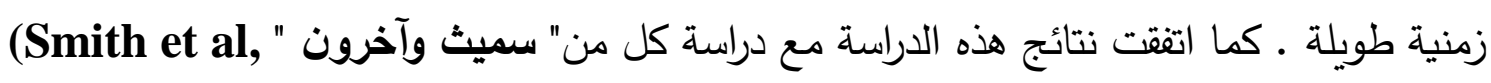
(2013 ، ودراسة "بين وابترجافت" (Pain \& Ubtgraft, 2010) في أن البرنامج التدريبي المستخدم عمل على تحسين الحد الأقصي لإستهلاك الأكسجين النسبي (CHRISTIAN): (5aine) (172-159 : Smith)(240 كما أظهرت نتائج الدراسة عدم وجود فروق ذات دلالة إحصائية بين القياسين القبلي والبعدي لأفراد المجموعة التجريبية على متغيرات (مؤشر كتلة الجسم ، ومعدل الأيض الأساسي ، وكتلة الشحوم) حيث حقق متغير كتلة الجسم معدل تغير وصل إلى (1.7\%) ، وحقق متغير معدل الايض 
الأساسي معدل تغير وصل إلى (3.6\%) ، وأخيرًا حقق متغير كتلة الثحوم معدل تغير وصل إلى • (\%1.6) وترى الباحثة أن السبب المباشر للتغير في مؤشر كتلة الجسم وإن كان تغيرًا غير دال ، إنما يعود

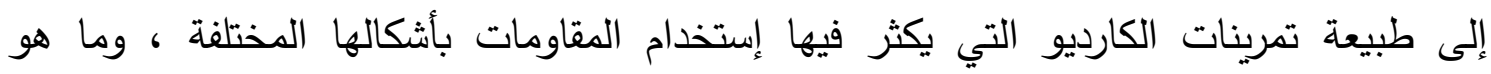

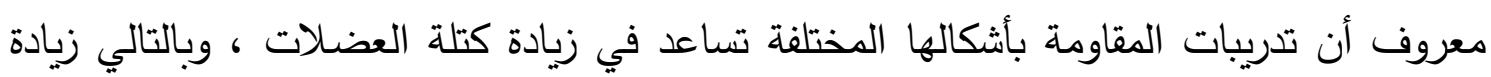

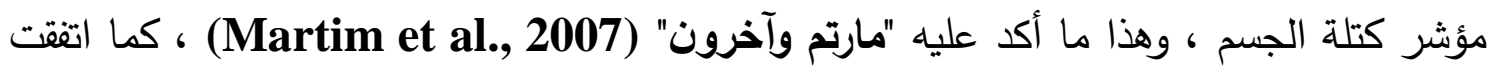
في ذلك مع ما جاء به "يوربينا وهايوارد" (Urbina \& Hayward, 2013) بوجود تأثير

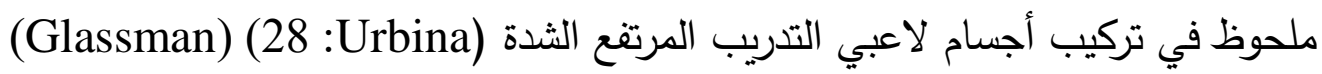

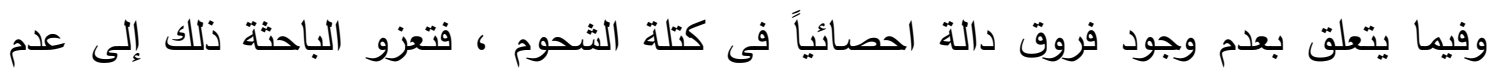

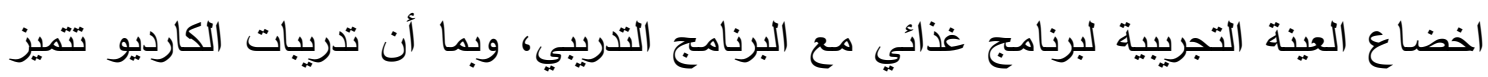

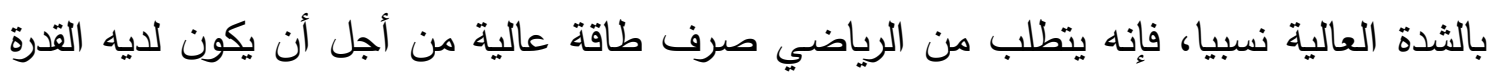

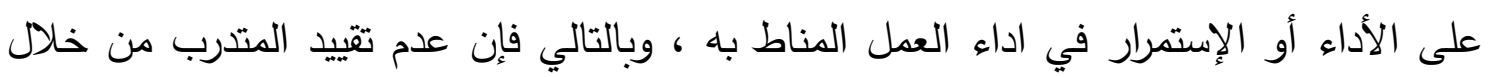

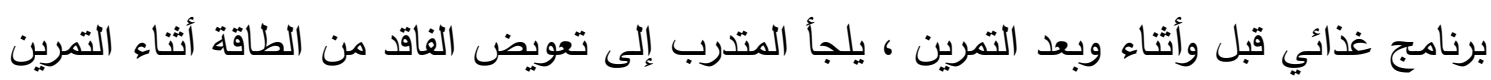

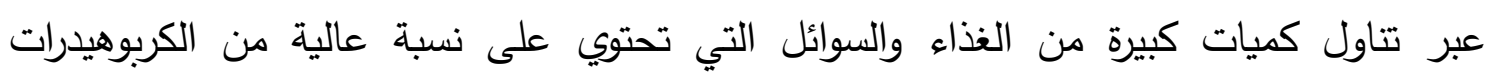
والعناصر الغذائية الأخري بشكل غير مقنن.

مناقثة النتائج المتعلقة بالتساؤل الثاني والذي ينص على : " هل توجد فروق ذات دلالة إحصائية

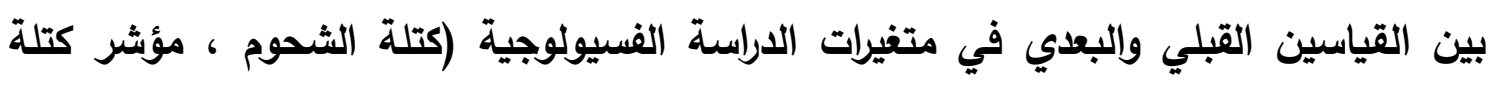
الجسم ، القدرة اللالأكسيجينة ، السعة اللاأكسجينية ، الحد الأقصي لاستهلاك الأكسجين

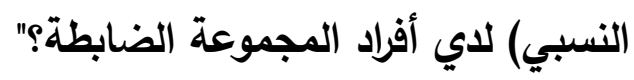
وبالنظر إلى القيم الواردة في الجدول (5) نلاحظ عدم وجود فروق ذات دلالة احصائية عند مستوي

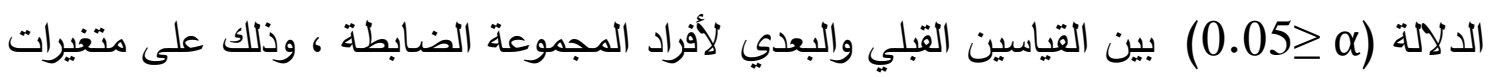

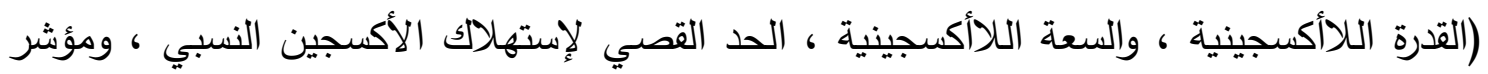

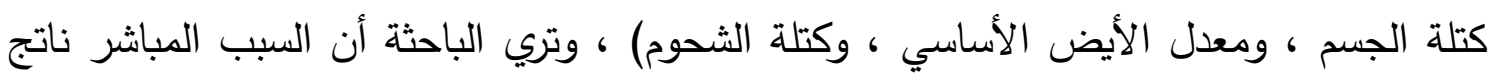

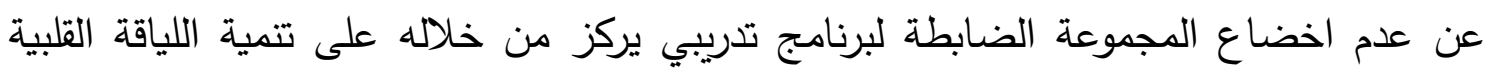

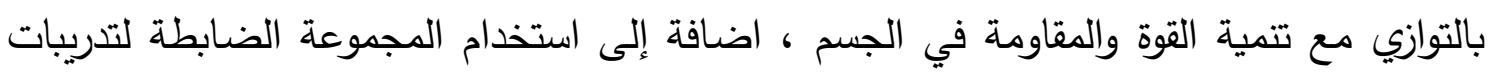
الايروبيك والتي يستخدم فيها مجموعة من التمارين لأجزاء مختلفة من اجسامهم. وجاءت نتائج هذه التغيرات للمجموعة الضابطة متفقة مع دراسة "جيرهات" (Gerhart, 2013) ،

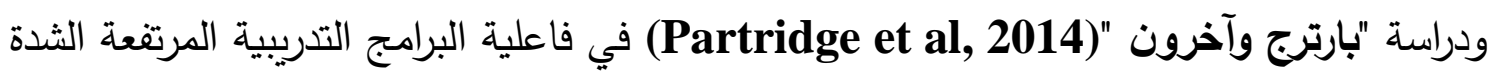


لصالح المجموعة التجريبية بعيدا عن اسلوب التدريب التقليدي (Gerhat: Partridge) (113) (721-714

مناقثة النتائج المتعلقة بالتساؤل الثالث والذي ينص على : " هل توجد فروق ذات دلالة إحصائية بين أفراد المجموعتين التجريبية والضابطة في القياس البعدي على جميع متغيرات الدراسة

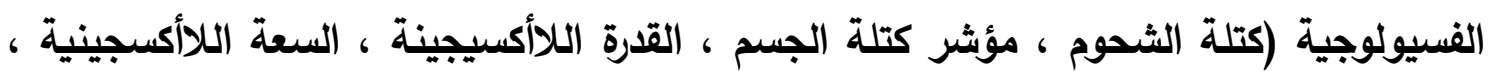

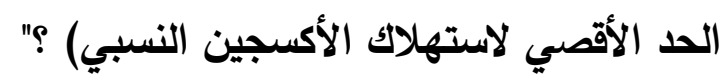

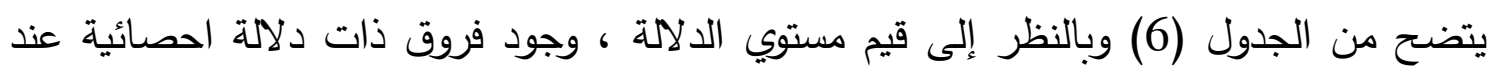

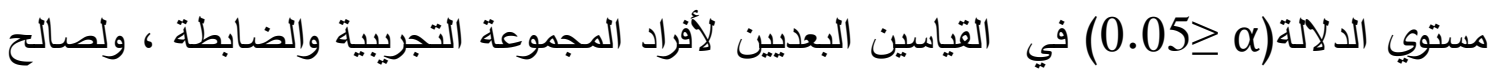

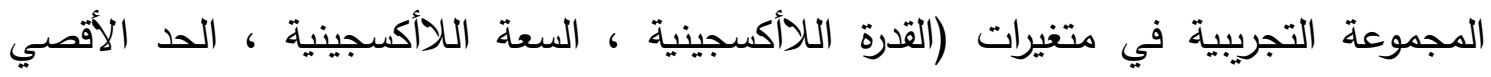

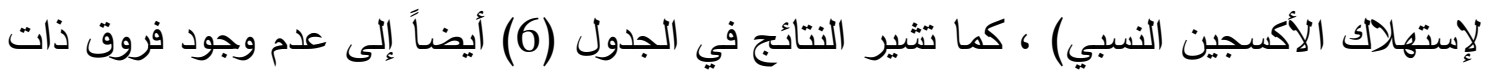

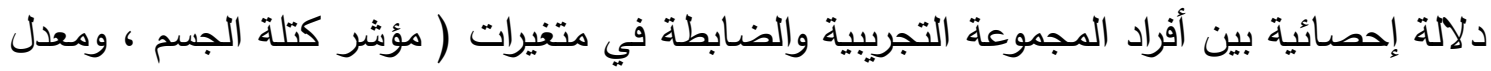
الأيض الأساسي ، وكتلة الثحوم). وترى الباحثة أن السبب المباشر في وجود فروق بين أفراد المجموعتين لصالح المجموعة التجريبية

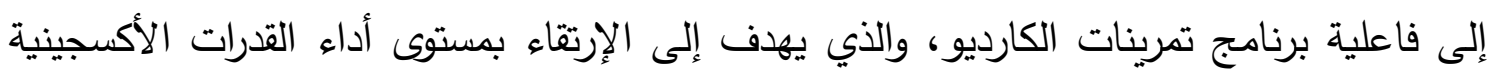

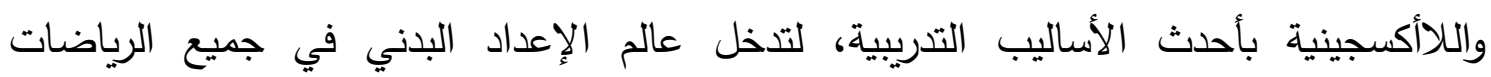
التخصصية.

كما يلاحظ بأن هذه الفروق والتغيرات لصالح الهموعة لتجريبية جاءت متفقة مع دراسة "بين

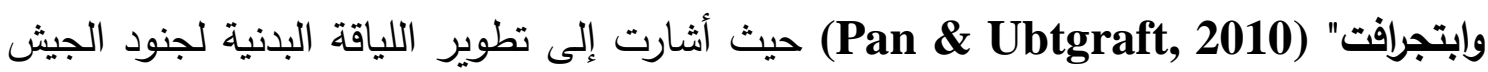

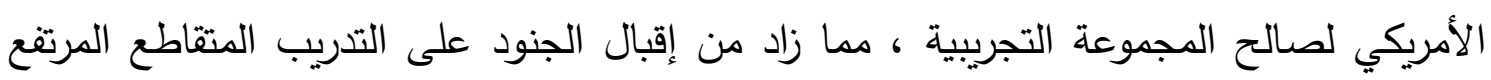

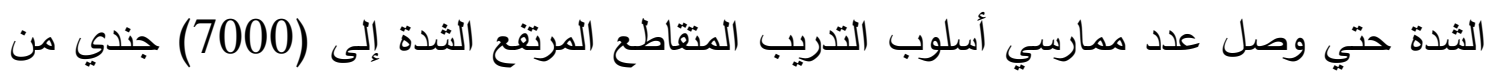

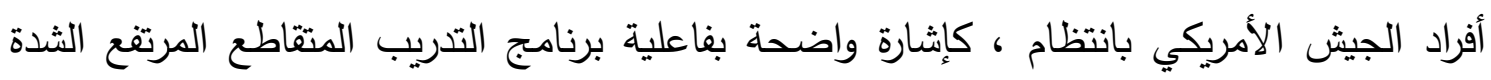

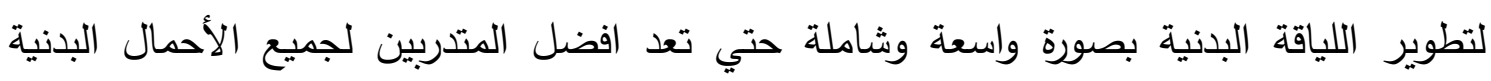
(5 :Paine)

كما أن تفوق المجموعة التجريبية على الضابطة في متغيرات (القدرة اللاأكسجينية ، السعة

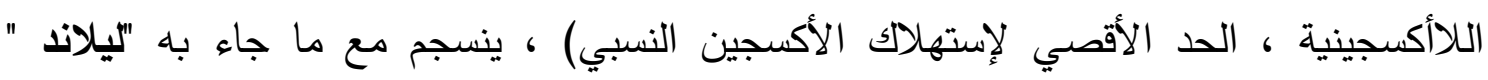

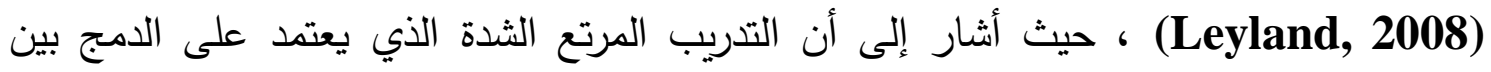
تدريبات المقاومة والتدريبات الأكسجينية القلبية يؤدي إلى زيادة كفاءة عمليات إنتاج الطاقة الأكسجينية والناأكسجينية ، وذلك من خلال زيادة نشاط الإنزيمات المسؤولة عن عمليات التتاج 
الطاقة اللاأكسجينية ، مما يساهم في الإرتقاء بكل من القدرة والسعة اللاأكسجينية ، وكذلك الحفاظ

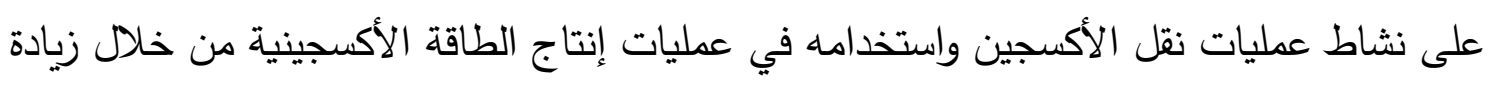
عمليات الأكسدة ، من يؤدي إلى الإرتقاء بالحد الأقصي لإستهلاك الأكسجين النسبي (Leyland: كما تتقق تلك النتائج مع ما اشار اليه كل من "جيرهات " (Gerhat, 2013) و"سميث وآخرون" أن التدريب المرتفع بشدة يساهم في تطوير الحد الأقصي لاستهلاك (Smith et al., 2013)

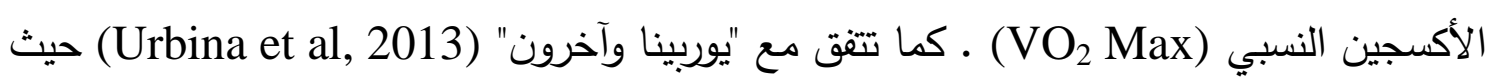
أشاروا إلى أن التدريب المرتفع الثدة يؤدي إلى الارتقاء بالقدرات اللاأكسبينة والأكسجينية ، حيث التيث

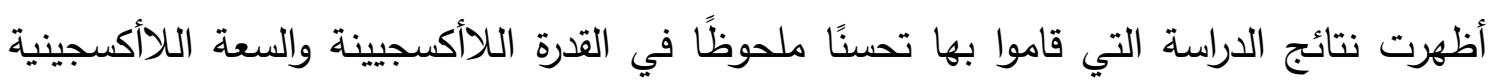

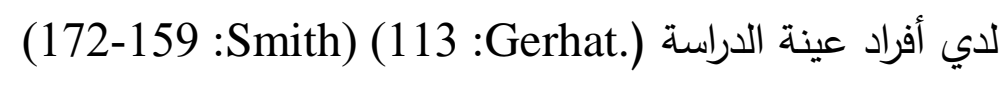
تاسعاً: الإستنتاجات وإلتوصيات:

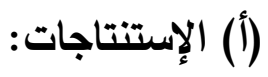

في ضوء نتائج الدراسة ومناقشتها تستتنج الباحثة ما يلي: الإني

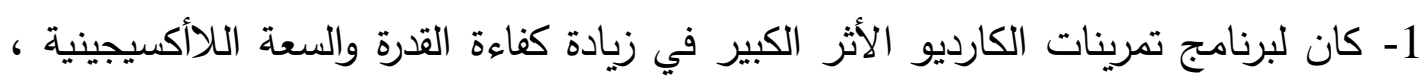

وبالتالي الارتقاء بمستوي الأداء البدني اللاأكسجيني.

2- ساهم برنامج تمرينات الكارديو في الارتقاء بمعدل الحد الأقصي لإستهلاك الإكسجين

$$
\text { النسبي عند المشتركات. }
$$

3- برنامج تمرينات الكارديو ساهم في الارتقاء بالكفاءة الأكسجينية واللاأكسيجينية للفرد

$$
\text { الرياضي. }
$$

4- برنامج تمرينات الكارديو أحدث تغيرات طفيفة في متغيرات الدراسة المتعلقة بـ (كتلة

$$
\text { (الثحوم ، ومؤشر كتلة الجسم). }
$$

(ب) (التوصيات:

في ضوء نتائج الدراسة واستنتاجاتها أوصت الباحثة بما يلي:

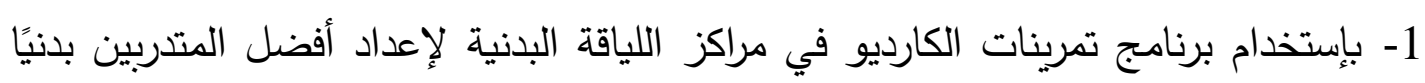

$$
\text { وفسيولوجيًا والتمتع بحجم دهون مناسب ومؤشر كتلة جسم معتدل. }
$$

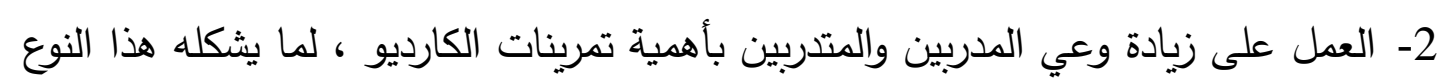

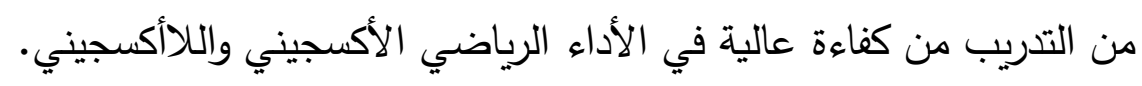

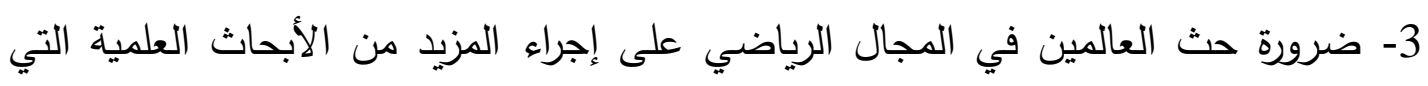

$$
\text { تتناول موضوع تمرينات الكارديو. }
$$




\section{قائمة المراجع

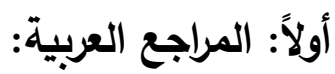

1- أمل حسين السيد (2003): "دراسة تتبعية عن مدي تأثير ممارسة التدريب الهوائي على زيادة البروتينات الدهنية مرتفعة الكثافة وتقليل البروتينات الدهنية منخفضة الدئة الكثافة في الدام

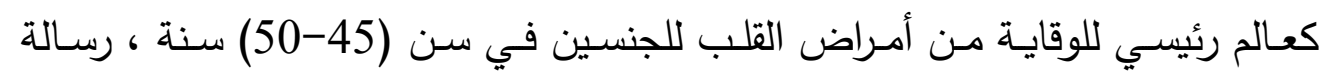

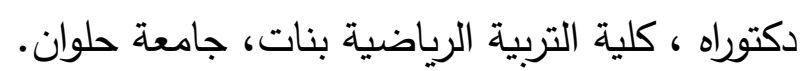

2- بهاء الدين سـلامة (2008): "الخصـائص الحيويـة لفسيولوجيا الرياضـة" ، دار الفكر العربي ،

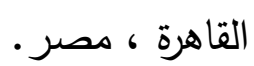

3- سها عبد الله السملاوى (2007): "تأثير برنامج تمرينات هوائية على دهون الدم لانقاص الوزن للسيدات "، رسالة ماجستير ، كلية التربية الرياضية ، جامعة طنطا.

4- سوسن فرغلي أحمد (2011): " تأثير برنامج تدريبي للتمرينات الهوائية على بعض المتغيرات البدنية ومستوي الاكتئاب للسيدات من 45: 50 سنة"، رسالة ماجستير كلية التربية الرياضية ، جامعة إلمنيا.

5- عايدة محمد حسين (2012): " تأثير برنامج التمرينات الهوائية باستخدام التدليك على إنقاص الـوزن والكفـاءة الوظيفيـة لـدي السيدات البـدينات"، رسـالة ماجستير ، كليـة التربيـة

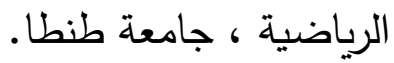
ثانياً: المراجع الأجنبية:

6- Calabro, P. (2008): Intra-abdominal adiposity, inflammation, and cardiovascular risk: new insight into global cardiometabolic risk. Curr Hypertens Rep., 10 .

7- CHRISTIAN LARSON (2015): VO2MAX EFFORT LIFT,cfj, 09, Fick3_Larson2.pfd.

8- Gerhat. D. Haden, (2013): A Comparison of Crossfit Training to Traditional Anaerobic Resistance Trainingin Termosf Selected Fitness Domains Representative of Overall athletic Performacnes. Univeristy of Pmyeylvania, august, Indiana.

9- Glassman Grej. (2007): Understanding Crossfit. Crossift journal 56 april. Usa. 
10- Gormley SE, Swain DP, High r, Spina RJ, Dowling EA, Kotipalli US, (2008): Effect of Internstiy of Aerobic Tranining on VO2MAX Med Sci Sport Exerc, 40(7).

11- Jonathan Myers, (2003): Exercise and Cardiovascular Health, Circulation, 107:e2-e5.

12- Len Kravits. Lance Dalleck (2008): Lactate Thershold Training, Hypemuscle, Canads Largest onlinebody building And fitness community, 19-40. Canada.

13- Leyland Tony (2008): Human Power Output and crossfit metcon Workouts. Exphysiology, Reference, July 01, crossfit Jounal Issue 71, Usa.

14- Lounana J, Campion f, Noakes TD, Medelli J. (2007): Relationshipebetween \% HRmax, \%HR reserve, \%VO2Max, and \%VO2reserve in elite cyclists. Med Sci Sports Exerc., 39(2):350-7.

15- Mannie Ken (2004): Michigan State Football Conditioning Program Hypemuscle, Canads Largest onlinebody building And fitness community, 05-08. Canada.

16- Masi SI, Charakida M, Wang G, O'Neill F, Taddei S, Deanfield J. (2009): Hope for the future: early recognition of increased cardiovascular risk in children and how to deal with it, Eur $\mathbf{J}$ Cardiovasc Prev Rehabil.: 16 Suppl 2:S 61-4.

17- National Institute for Health and Clinical Excellence, Clinical guideline 181, (2014): Lipid modification, cardiovascular risk assessment and the modification of blood lipids for the primary and secondary prevention of cardiovascular disease. London.

18- Paine Jeffry, James U., \& Ryan W. (2010): Crossfit Study. Command and General Staff College. Omb number 0704-0188 P.5 ,. Usa.

19- Partridge, JA, Knapp, BA, and Massengale, BD. (2014): aninvestigation of motivatinal variables in Crossfit facilities, J. Strength Cond Res 28(6): 714-721.

20- Smith, MM, Sommer, AJ, Starkoff, BE, and Devor, ST. (2013): Crossfitbased high-intensity power training improves maximal aerobic fitness and body composition. J. Strength Cond Res 27(11)" 159-172.

21- Urbina Stacie, Sara Hayward (2013): Human performance, University of mary Hardin Jouranl of international society of sports nutritatin, college street, 10 Dec, P 28. Usa 
22- Wilmore, Jack, H, Costill, David I, Kennety, W Larry (2008): Physiology of sport and Exercise. Human Kinetics, library of congress cataloging. United state.

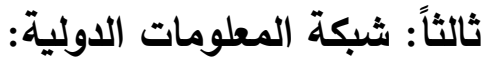

23- http://athleteculture.com/training/doing-cardio-workouts-and-excrcises-the-right-way,by Nick Coe, Published on April 18 2013.

24- http://athleteculture.com/training/hep-how-to-train-my-overweight-partner, by Joe starrks, published on January 32st, 2014.

25- http://www.cvphysiology.com/Cardiac\$20Funciton/CF02-24

26- https://www.myfitness.lv/eng/trainings/cardio.

27- https://www.nhs.uk/livewell/fitness/pages/home-cardio-workout

28- https://www.sharecare.com/health/cardiovascular-traiing/what-is-cardio

29- http://thescienceofeating.com/cardio-workouts.

30- https://www.ubeingfit.com/what-are-cardio-exercises.

31- https://www.ekeyledg.com/11/cardio-wrokout 